\title{
Glutamate controls vessel-associated migration of GABA interneurons from the pial migratory route via NMDA receptors and endothelial protease activation
}

\author{
Cécile Léger ${ }^{1}$. Nicolas Dupré ${ }^{~}$. Caroline Aligny ${ }^{1} \cdot$ Magalie Bénard $^{4}$ - Alexis Lebon ${ }^{4}$. Vincent Henry ${ }^{1}$. \\ Michelle Hauchecorne ${ }^{1} \cdot$ Ludovic Galas $^{4}$. Thierry Frebourg ${ }^{1} \cdot$ Philippe Leroux $^{1}$ - Denis Vivien ${ }^{2,3}$. \\ Maryline Lecointre ${ }^{1}$. Stéphane Marret ${ }^{1} \cdot$ Bruno J. Gonzalez $^{1}$
}

Received: 7 September 2018 / Revised: 8 July 2019 / Accepted: 23 July 2019 / Published online: 7 August 2019

(c) The Author(s) 2019

\begin{abstract}
During cortex development, fine interactions between pyramidal cells and migrating GABA neurons are required to orchestrate correct positioning of interneurons, but cellular and molecular mechanisms are not yet clearly understood. Functional and age-specific expression of NMDA receptors by neonate endothelial cells suggests a vascular contribution to the trophic role of glutamate during cortical development. Associating functional and loss-of-function approaches, we found that glutamate stimulates activity of the endothelial proteases MMP-9 and t-PA along the pial migratory route (PMR) and radial cortical microvessels. Activation of MMP-9 was NMDAR-dependent and abrogated in t-PA ${ }^{-1-}$ mice. Time-lapse recordings revealed that glutamate stimulated migration of GABA interneurons along vessels through an NMDAR-dependent mechanism. In Gad67-GFP mice, t-PA invalidation and in vivo administration of an MMP inhibitor impaired positioning of GABA interneurons in superficial cortical layers, whereas Grin1 endothelial invalidation resulted in a strong reduction of the thickness of the pial migratory route, a marked decrease of the glutamate-induced MMP-9-like activity along the PMR and a depopulation of interneurons in superficial cortical layers. This study supports that glutamate controls the vessel-associated migration of GABA interneurons by regulating the activity of endothelial proteases. This effect requires endothelial NMDAR and is t-PA-dependent. These neurodevelopmental data reinforce the debate regarding safety of molecules with NMDA-antagonist properties administered to preterm and term neonates.
\end{abstract}

Keywords Endothelial cells $\cdot$ GABA interneuron $\cdot$ Migration $\cdot$ MMP-9 $\cdot$ NMDAR $\cdot$ t-PA

Nicolas Dupré and Caroline Aligny have equally contributed to this work.

Electronic supplementary material The online version of this article (https://doi.org/10.1007/s00018-019-03248-5) contains supplementary material, which is available to authorized users.

Bruno J. Gonzalez

bruno.gonzales@univ-rouen.fr

1 Normandie University, UNIROUEN, INSERM U1245 and Rouen University Hospital, Department of Neonatal Paediatrics and Intensive Care, F 76000, Normandy Centre for Genomic and Personalized Medicine, Rouen, France

2 Inserm, Université Caen-Normandie, Inserm, UMR-S U1237 "Physiopathology and Imaging of Neurological Disorders" (PhIND), GIP Cyceron, Caen, France

$\begin{array}{ll}\text { Abbreviations } \\ \text { aCSF } & \text { Artificial cerebrospinal fluid } \\ \text { CR } & \text { Calretinin } \\ \text { DCX } & \text { Doublecortin } \\ \text { MMP-9 } & \text { Matrix metalloproteinase 9 } \\ \text { PAI-1 } & \text { Plasminogen activator inhibitor 1 } \\ \text { PMR } & \text { Pial migratory route }\end{array}$

3 Department of Clinical Research, Caen University Hospital, CHU Caen, Caen, France

4 Normandie University, UNIROUEN, INSERM, PRIMACEN, Rouen, France 
SST

Somatostatin

t-PA

Tissue-plasminogen activator

\section{Introduction}

At the cellular and molecular levels, there is increasing evidence that, in the developing cortex, endothelial cells are not phenotypically or regionally similar [1,2]. For example, in the mouse, the transcriptomic and proteomic expression profiles of cortical microvessels revealed age-dependent specificities that will drastically change postnatally because of strong remodeling of the extracellular matrix, cell adhesion, and junction protein expression [1]. Similarly, at a given developmental stage, endothelial cells of the pial surface have phenotypic identities distinct from those of the periventricular vascular network, suggesting distinct contributions to the developing brain [2]. Consistent with this notion, meninges have been shown to release chemoattractive factors such as the chemokine $\mathrm{CXCl} 12$ essential in the control of nervous cell migration [3,4]. Interestingly, it has been shown that there are region-specific and age-specific changes in the expression of both NMDA receptor subunits and excitatory amino acid transporters by neonatal endothelial cells $[5,6]$ and in vitro studies showed that NMDA is able to promote secretion of two endothelial proteases, i.e., matrix metalloproteinase-9 (MMP-9) and tissue-plasminogen activator (t-PA) by cultured neonatal endothelial cells [6]. These two proteases are involved in the control of cell migration in physiological and/or pathological conditions $[7,8]$ and the preferential expression pattern of NMDA receptors by endothelial cells during the perinatal period coincides with the late migration of GABA interneurons [9]. Because it has been demonstrated that during cortical development, interneurons migrate tangentially while closely interacting with the vasculature of the pial migratory route (PMR) $[2,10,11]$, these data suggest that the endothelial NMDA receptor would contribute in the vessel-associated interneuron migration. Consistent with this hypothesis, several recent data showed that the migration of GABAergic neurons is regulated by excitatory neurons [12] and that exposure of mouse neonate cortices to molecules with NMDA-antagonist properties such as ketamine, alcohol, or MK801 resulted in endothelial cell autophagy followed by massive apoptotic death of migrating tangential GABA interneurons present in the superficial cortical layers [13-17].

In humans, late migration of GABAergic neurons has also been reported with at least $20 \%$ of interneurons still migrating in the developing cortex at term [18]. Moreover, at the clinical level, the brains of preterm and term neonates can be frequently exposed to molecules with NMDA-antagonist properties during the early life for the purposes of neuroprotection or anesthesia [19-21]. In addition, the innocuousness of NMDA antagonists in the developing brain is not consensual and it is more and more suspected a functional link between NMDA receptor hypofunction during early life and impaired positioning of GABA interneurons that could lead to adult diseases [22-24].

In the present study, we reported that glutamate by interacting with endothelial NMDA receptors stimulates the activity of endothelial proteases, increases vessel-associated cell migration, and contributes to the positioning of GABA interneurons arising from the pial migratory route to radially enter the cortex. These data provide new evidence that the activation of the endothelial NMDA receptors by glutamate constitutes a mechanism involved in the control of the vasculo-associated migration of cortical interneurons.

\section{Materials and methods}

\section{Wild-type and transgenic mice}

For each mouse strain, animals were kept in a temperaturecontrolled room $\left(21 \pm 1{ }^{\circ} \mathrm{C}\right)$ with a 12 -h/12-h light/dark cycle (lights on from 7:00 a.m. to 7:00 p.m.) and free access to food and water. Animal care and manipulation complied with recommendations issued by the French and European guidelines for the care and use of laboratory animals (Council Directive 86/609/EEC, license no. 21CAE035), and were supervised by an authorized investigator (B.J.G., authorization no. 7687 from the Ministère de l'Agriculture et de la Pêche). Naval Medical Research Institute mice were purchased from Janvier (Le Genest Saint Isle, France). FVB$\operatorname{Tg}$ (GadGFP)45704Swn transgenic mice (\#003718) were obtained from the Jackson Laboratory (Bar Harbor, ME). In this mouse strain, GABAergic interneurons arising from the GEs express enhanced green fluorescent protein under the control of the mouse Gad1 gene promoter [25]. t-PA knockout (t-PA ${ }^{--}$) mice in the C57B16/129 background $\left(\mathrm{t}-\mathrm{PA}^{-1-}\right.$ in a ratio of $\left.87.5: 12.5 \%\right)$ were developed and provided by the Center for Molecular and Vascular Biology at the University of Leuven in Belgium [26]. Double transgenic Gad67GFP/t-PA ${ }^{-1-}$ mice were developed by Inserm U1245. Floxed Grin1 mice (B6.129S4-Grin1tm2Stl/J; \# 005246) were from The Jackson Laboratory. Floxed Grin1 mice allow deletion of the GluN1 subunit of the $N$-methylD-aspartate receptor in Cre recombinase expressing cells/ tissues. VE-Cadherin-Cre (B6.FVB-Tg(Cdh5-cre)7Mlia/J; \# 006137) were from The Jackson Laboratory. Cre expression can be seen in the embryo and in adult endothelium of developing and quiescent vessels. 


\section{Chemicals}

Glutamate, Coomassie blue, Hoechst 33258, isolectin-B4TRITC/FITC, phosphate-buffered saline (PBS), bovine serum albumin (BSA), plasminogen activator inhibitor 1 (PAI-1), and Triton X-100 were from Sigma-Aldrich (Saint Quentin Fallavier, France). MK801 was obtained from Tocris (R\&D, Lille, France). GM6001 was provided by Millipore SAS (Molsheim, France). SDS-PAGE Tris-glycine gel (containing $0.1 \%$ gelatin as a gelatinase substrate), renaturing buffer, developing buffer, DQ-gelatin-FITC, and DQcasein-FITC were from Invitrogen (Cergy Pontoise, France). The gelatinase inhibitor SB-3CT was from Biomol (Lonza Sales Ltd, Basel, Switzerland). Paraformaldehyde (PFA) was obtained from Labonord (Templemars, France). Characteristics of the primary antibodies against alpha-smooth muscle actin (ACTA2), CD31, calretinin, Cre recombinase, collagen IV, doublecortin (DCX), GABA, GFAP, GFP, GluN1, MMP9, somatostatin (SST), Gad67, and $\beta$-actin are summarized in Supplementary Table 1. The secondary antibodies Alexa Fluor 488 donkey anti-rabbit IgG (A-21206), Alexa Fluor 488 goat anti-rat (A-11006), and Alexa Fluor 594 donkey anti-goat IgG (A-11058) used for immunohistochemistry were from invitrogen.

\section{Genotyping by polymerase chain reaction}

Mouse tail DNAs were extracted using NucleoSpin ${ }^{\circledR}$ DNA Rapidlyse (Macherey-Nagel, Düren, Germany) and were amplified on a thermal cycler with the following program: 2 min, $94{ }^{\circ} \mathrm{C} ; 2 \mathrm{~s}, 94{ }^{\circ} \mathrm{C} ; 15 \mathrm{~s}, 65-0.5^{\circ} \mathrm{C}$ per cycle decrease; $10 \mathrm{~s}, 68^{\circ} \mathrm{C}$; repeats step $2-4$ for ten cycles; $10 \mathrm{~s}, 94{ }^{\circ} \mathrm{C} ; 15 \mathrm{~s}$ $50{ }^{\circ} \mathrm{C} ; 10 \mathrm{~s}, 72{ }^{\circ} \mathrm{C}$, repeats step $3-5$ for 28 cycles; $2 \mathrm{~min}$, $72{ }^{\circ} \mathrm{C}$. Genotyping was performed with primers provided by the Jackson Laboratory; Grin1 5'-AAACAGGGCTCA GTGGGTAA and 3'-GTGCTGGGATCCACATTCAT; Cre transgene 5'-GCGGTCTGGCAGTAAAAACTATC and 3'-GTGAAACAGCATTGCTGTCACTT. Electrophorese was conducted on $3.5 \%$ of agarose gels and visualized with ethidium bromide.

\section{Preparation of cortical microvessels and Grin 1, Grin2a, and Grin2b qRT-PCR}

Freshly isolated cortical microvessels were prepared as previously described [6]. Practically, cortices from P10 mouse neonates (20 animals per group) were homogenized in a Dounce tissue homogenizer in $10 \mathrm{~mL}$ molecular cellular and developmental biology (MCDB) medium 131 supplemented with $2 \%$ of FCS (fetal calf serum), $100 \mathrm{U} / \mathrm{mL}$ penicillin, and $100 \mathrm{mg} / \mathrm{mL}$ streptomycin (all from GIBCO, Invitrogen, Cergy Pontoise, France). The homogenate was centrifuged at $200 \mathrm{~g}$ for $15 \mathrm{~min}$ at $4{ }^{\circ} \mathrm{C}$. The pellet was suspended in $18 \%$ (w/v) dextran solution (Sigma-Aldrich, Saint Quentin Fallavier, France) and centrifuged at $2,000 \mathrm{~g}$ for $45 \mathrm{~min}$ at $4{ }^{\circ} \mathrm{C}$. Thereafter, it was suspended in PBS $1 \mathrm{X}$ and filtered using a $70 \mu \mathrm{m}$ cell strainer (Falcon, BD Biosciences, Pont de Claix, France). The resulting microvessel filtrate was centrifuged at $200 \mathrm{~g}$ for $7 \mathrm{~min}$ at $4{ }^{\circ} \mathrm{C}$. The pellet was suspended in $350 \mu \mathrm{L}$ of lysis buffer (Qiagen, Courtaboeuf, France) containing $1 \% \beta$-mercaptoethanol (Sigma-Aldrich) and ceramic beads for mechanical dissociation. Total RNAs were extracted using an RNeasy Micro kit (Qiagen) in accordance with the manufacturer's instructions. After DNase digestion, cDNA was prepared from $100 \mathrm{ng}$ total RNA using the QuantiTect reverse transcription kit (Qiagen). Generation of polymerase chain reaction (PCR) products was measured in real time by incorporation of the fluorescent dye SYBR Green I using a Light Cycler 96 real-time PCR system (Roche, Mannheim, Germany). For each reaction, a master mix was prepared as follows: 1X SYBR Green buffer (Biorad), and $0.5 \mathrm{mM}$ sense and antisense primers (Invitrogen). PCR products for Grin1, Grin2A and Grin2B subunits of the NMDA receptor were generated using primers described in Supplementary Table 2. All PCRs were performed using the cycle conditions: $95^{\circ} \mathrm{C}(10 \mathrm{~s}), 60{ }^{\circ} \mathrm{C}(30 \mathrm{~s})$, and $65-95^{\circ} \mathrm{C}(5 \mathrm{~s})$, and were run for a total of 40 cycles. PCR amplification efficiency was assessed for each primer set from the slope of a standard curve generated with serial dilutions of cortical cDNA which was close to 3.3 for all primers, indicating maximal PCR amplification efficiency. The PCR product purity was verified using dissociation curves. The cDNA amount in each sample was calculated using the comparative threshold cycle $(\mathrm{Ct})$ method and expressed as $2^{-\Delta \Delta \mathrm{Ct}}$ using glyceraldehyde-3-phosphate dehydrogenase (GAPDH) as an internal control.

\section{Preparation and treatment of cerebral slices from neonate mice}

Cortex brain slices were obtained from mice on postnatal day 2 (P2). Previous studies demonstrated that this stage presented developmental and lesional characteristics similar to those described for human neonates [27, 28]. Practically, mice were euthanized by decapitation and brains were rapidly dissected to isolate the hemispheres. The neocortex was immediately placed in ice-cold artificial cerebrospinal fluid (aCSF) containing (in $\mathrm{mM}$ ) the following: $\mathrm{NaCL}, 125$; KCL, $3 ; \mathrm{CaCl}_{2}, 2 ; \mathrm{NaH}_{2} \mathrm{PO}_{4}, 1.2 ; \mathrm{NaHCO}_{3}, 26$; and D-glucose, 10 (pH 7.4). Transverse slices $(250 \mu \mathrm{m})$ were cut at $4{ }^{\circ} \mathrm{C}$ using a vibratome (VT1000S; Leica, Reuil-Malmaison, France), transferred into 24-well Costar plates (Cambridge, MA) containing aCSF, and incubated during a recovery period of $30 \mathrm{~min}$ at $37^{\circ} \mathrm{C}$ in a humidified incubator with a controlled atmosphere of $5 \% \mathrm{CO}_{2} / 95 \%$ air. Then, slices were washed with fresh aCSF and treated for $3 \mathrm{~h}$ at $37{ }^{\circ} \mathrm{C}$ with glutamate 
(25, 50, $100 \mu \mathrm{M}), \mathrm{MK} 801(20 \mu \mathrm{M})$, SB-3CT $(10 \mu \mathrm{M})$, and PAI-1 $(5 \mathrm{nM})$ alone or in combination.

\section{SDS-PAGE gelatin and casein zymography}

Gelatin zymograms were used to reveal matrix metalloproteinase-2 (MMP-2) and MMP-9 activities. Casein zymograms were used to reveal t-PA activity. Experiments were performed in $\mathrm{P} 2$ cortical extracts. Practically, microdissected cortices were washed in fresh aCSF and homogenized in $50 \mu \mathrm{L}$ of lysis buffer $(50 \mu \mathrm{M}$ Hepes; $\mathrm{pH} 7.5 ; 150 \mathrm{mM} \mathrm{NaCl}$; $10 \mathrm{mM}$ EDTA; $10 \mathrm{mM}$ glycerophosphate; $100 \mathrm{mM}$ natrium fluoride; $1 \%$ Triton $\mathrm{X}-100$ ). After centrifugation of the homogenates $(20,000 \mathrm{~g} \times 15 \mathrm{~min})$, the supernatants were collected and protein concentrations were determined by the Bradford assay. Proteins were loaded as 15 and $30 \mu \mathrm{g} / \mathrm{well}$ for gelatin and casein zymography, respectively, and separated by electrophoresis. For gelatin zymography, the gels were incubated in renaturing buffer (Triton X-100, $12.5 \mathrm{~mL}$; $\mathrm{H}_{2} \mathrm{O}, 487.5 \mathrm{~mL}$ ) for $30 \mathrm{~min}$ at room temperature and in developing buffer (glycine, $3.75 \mathrm{mM}$; EDTA, $1.45 \mathrm{mM}$ ) for another $30 \mathrm{~min}$ at room temperature. After transfer in fresh developing buffer, gels were incubated for 5 days at $37{ }^{\circ} \mathrm{C}$, stained in $0.5 \%$ Coomassie blue for $1 \mathrm{~h}$, and rinsed for $1 \mathrm{~h}$ in distilled water. Light stripes on a blue background indicated gelatin digestion of the gel by gelatinases. For casein zymography, gels were incubated in renaturing buffer at $4{ }^{\circ} \mathrm{C}$ overnight and rinsed in water for $30 \mathrm{~min}$ at $4{ }^{\circ} \mathrm{C}$. Then, gels were transferred in developing buffer for $3 \mathrm{~h}$ and $30 \mathrm{~min}$ at $37^{\circ} \mathrm{C}$ and stained with $0.5 \%$ Coomassie blue for $1 \mathrm{~h}$. Finally, they were de-stained in $40 \%$ methanol and $10 \%$ acetic acid for $30 \mathrm{~min}$ at room temperature. Light stripes on a blue background indicated casein digestion of the gel by t-PA. Digital images of the gels were acquired and digestion stripes were quantified using Explora Nova Mercator Software (La Rochelle, France).

\section{In situ gelatinase and casein zymography on brain slices}

In situ MMP and casein zymography were performed for $250-\mu \mathrm{m}$ brain slices from wild-type (WT), t-PA ${ }^{-/-}$or $\mathrm{Grin} 1^{\mathrm{lox} / \mathrm{lox}} / \mathrm{VeCad}{ }^{\mathrm{Cre}}$ mice previously stained by isolectinB4-TRITC to visualize the pial migratory route. Slices were incubated for $30 \mathrm{~min}$ in aCSF containing isolectin-B4TRITC $(1 / 50)$ at $37{ }^{\circ} \mathrm{C}$ in a humidified incubator under a controlled atmosphere of $5 \% \mathrm{CO}_{2} / 95 \%$ air. After two washes for $10 \mathrm{~min}$ with aCSF, slices were incubated for $3 \mathrm{~h}$ with the quenched gelatinase substrate DQ-gelatin-FITC (1/50) or DQ-casein-FITC (1/125) in the presence of glutamate $(100 \mu \mathrm{M}), \mathrm{MK} 801(20 \mu \mathrm{M})$, and/or SB-3CT $(10 \mu \mathrm{M})$ alone or in combination. Quantification of FITC fluorescence, indicative of cell-specific digestion of the substrate, was performed by time-lapse recordings using a fluorescent videomicroscope system (DMI 6000B; Leica, Reuil-Malmaison, France) coupled to the Explora Nova Mercator Software. Microphotographs were acquired at $488 \mathrm{~nm}$ and $540 \mathrm{~nm}$ every $15 \mathrm{~min}$ for $3 \mathrm{~h}$ to follow the kinetics of DQ-gelatinFITC and DQ-casein-FITC degradations and to visualize cortical microvessels from the pial migratory route, respectively. A background level was defined in a negative region of the slice.

\section{Laser capture microdissection and GluN1 qRT-PCR}

Transverse slices $(250 \mu \mathrm{m})$ were cut in ice-cold aCSF using a vibratome (VT1000S; Leica, Reuil-Malmaison, France) and stained with isolectin-B4-TRITC. Slices were transferred to FrameSlides with polyethylene terephthalate (PET, Steel frames, PET-membrane; Leica, Reuil-Malmaison, France), fixed in dry ice-cooled isopentane. Just before the LCM procedure, the samples were dehydrated for a few minutes with increasing concentrations of ethanol (70 and 100\%). The laser capture microdissection was performed using a Leica Microdissection apparatus (LMD6000, Leica Microsystems), by applying a pulsed UVA laser beam (focal spot $<5 \mu \mathrm{m}$ ) through an inverted microscope with $\times 5-20$ objectives (Supplementary Fig. 1a-e). After microdissection, vessel-enriched fractions were collected by gravity into a tube containing $60 \mu \mathrm{L}$ of lysis buffer (Qiagen, Courtaboeuf, France) with $1 \% \beta$-mercaptoethanol (Sigma-Aldrich). Total RNAs were extracted using an RNeasy Micro kit (Qiagen) in accordance with the manufacturer's instructions and eluted with $14 \mu \mathrm{L}$ of RNase-free water. DNase I treatment (RNaseFree DNase Set; Qiagen) was performed to remove contaminating genomic DNA. The quality of the RNAs was assessed (RIN between 5.2 and 6.9), and the quantity was estimated by microfluidic capillary electrophoresis (Agilent 2100 Bioanalyzer; Agilent Technologies, Massy, France). Approximately $20 \mathrm{ng}$ of RNA were reverse-transcribed in a $20-\mathrm{mL}$ reaction that contained 5× QuantiTec Buffer, RT Primer Mix and Quantiscript Reverse Transcriptase from a QuantiTec Reverse Transcription kit (Qiagen). Grin1 quantitative RTPCR was performed using primers 5'-CTCTAGCCAGGT CTACGCTATCC (sense) and 5'-GACGGGATTCTGTAG AAGCCA (antisense). GAPDH was detected with primers 5'-CATGGCCTTCCGTGTTCCTA (sense) and 5'-CCTGCT TCACCACCTTCTTGA (antisense).

\section{Immunohistochemistry}

Brain slices previously fixed with 4\% PFA in PBS were incubated overnight at $4{ }^{\circ} \mathrm{C}$ with various primary antibodies diluted in incubation buffer (PBS containing 1\% BSA and 3\% Triton X-100) (Supplementary Table 1). Then, the slices were rinsed three times with PBS for $20 \mathrm{~min}$ and 
incubated with the same incubation buffer containing an adequate secondary antibody. Cell nuclei were visualized by incubating slices for $5 \mathrm{~min}$ with $1 \mu \mathrm{g} / \mathrm{mL}$ Hoechst 33258 in PBS. Fluorescent signals were observed with a Leica DMI 6000B microscope. The intensity profiles of immunolabeled slices were done using the Line scan tool of the Metamorph software (Roper Scientific, Evry, France). Control for nonspecific binding of the secondary antibody was performed by omitting the primary antibodies.

\section{Western blot}

Microdissected cortices from WT and transgenic mice were rapidly homogenized in ice-cold lysis buffer. After centrifugation, supernatants were collected and protein concentrations were determined by the Bradford assay. The pellet was denatured at $100{ }^{\circ} \mathrm{C}$ for $5 \mathrm{~min}$ in $50 \mu \mathrm{L}$ of Tris/HCl (pH 7.5) containing $20 \%$ glycerol, $0.7 \mathrm{M}$ 2-mercaptoethanol, $0.004 \%(\mathrm{w} / \mathrm{v})$ bromophenol blue, and 3\% (w/v) sodium dodecyl sulfate (SDS), and then, it was electrophoresed on $10 \%$ SDS-polyacrylamide gel. After separation, the proteins were electrically transferred to a polyvinyldifluoridine membrane (PerkinElmer Life Sciences, Boston, MA). The membrane was incubated with blocking solution (5\% BSA in Tris-buffered saline containing $0.05 \%$ Tween 20 ) at room temperature for $1 \mathrm{~h}$ and incubated overnight with primary antibodies against somatostatin and actin (Supplementary Table 1). After incubation with the corresponding secondary antibodies coupled to peroxidase (Santa Cruz Biotechnology, Santa Cruz, CA), proteins were visualized using an enhanced chemiluminescence ECL Plus immunoblotting detection system (ECL; Bio-Rad Laboratories, Marne la Coquette, France). The intensity of the immunoreactive bands was quantified using a blot analysis system (Bio-Rad Laboratories), and $\beta$-actin was used as a loading control. Commercial markers (Seeblue pre-stained standard; Invitrogen) were used as molecular weight standards.

\section{Quantification of the vessel-associated GABAergic interneurons and measurement of the PMR thickness}

Quantification of vessel-associated GABAergic interneurons was performed after double immunostaining of P2 cortical slices with GABA and CD31 antibodies (Supplementary Table 1). Images were acquired and saved in TIFF format using a Leica TCS SP8 MP confocal microscope. Image resolution was $1024 \times 1024$ pixels and $\mathrm{z}$ stacks were done with a step ranging from 0.25 to $0.5 \mu \mathrm{m}$ (Supplementary Fig. 2d). X/Z as well as Y/Z sections of the acquired stacks were done using the IMARIS imaging software (Bitplane, Zurich, Switzerland) to validate the vessel-neuron interactions (Supplementary Fig. 2a-c). Images were subsequently opened in Leica LAS AF Lite software to quantify the distance between the outer part of the neuron and the outer part of the vessel (Supplementary Fig. 2e). Distances below $15 \mu \mathrm{m}$ were considered as representative of a vessel association (Supplementary Fig. 2e). Finally, the vessel density was quantified in the superficial and deep cortical layers, and this parameter was used to balance the vessel-associated vs not-associated proportion of GABA interneurons. The quantification of the PMR and cortical layer thicknesses in t-PA null mice and in Grin $1^{l o x} / l o x / \mathrm{VeCad}{ }^{C r e}$ mice was also performed using the Leica LAS AF Lite software.

\section{Quantification of GABA, Gad67, and somatostatin neuronal densities}

For measurements of GABA neuronal density in the superficial cortical layers of wild type, t-PA ${ }^{-/}$and Grin $1^{\text {flox } /}$ VeCadherin ${ }^{\mathrm{Cre}}$ mice, images were acquired at $20 \times$ magnification after different immulabeling using GABA, Gad67 or somatostatin antibodies. Practically, after a blind acquisition of the image at the tiff format, a background value was acquired using the Leica MM AF software powered by Metamorph V1.5. Then, the mean background value was subtracted using the "background correction" item. A region of interest (ROI) was defined within the superficial cortical layers and a segmentation done. The Metamorph analysis gave access to the number of objects (cell bodies) within the ROI and to the thresholded area/ROI area ratio. Morphometric analysis was then validated by the investigator to correct possible artefacts (for example, two fused cells counted as a single object or the presence of fluorescent debris). The analysis was repeated to cover the superficial layers I-IV from the somatosensory cortex in both hemispheres and in three slices per animal [29].

\section{Quantification of primary neurite density in double transgenic Gad67-GFP/t-PA ${ }^{-/-}$mice}

Quantification of primary neurite densities of GABA interneurons populating the cortical superficial layers was performed at P15 on both Gad67-GFP/t-PA ${ }^{\mathrm{WT}}$ and Gad67GFP/t-PA ${ }^{-1-}$ mice. A reference focal plane corresponding to the Gad67-GFP cell body was first defined with a confocal laser scanning microscope (Noran Instruments, Middleton, WI) using INTERVISION software (Noran Instruments). Then, Z-series of four images were acquired with a $2-\mu \mathrm{m}$ step on both sides of the reference plane and saved in TIFF format. Next, acquired images were deconvolved and compiled for three-dimensional (3D) reconstruction using AutoQuant $\mathrm{X}_{3}$ deconvolution software (Media Cybernetics, Rockville, MD) to quantify the number of primary neurites per cell body. 


\section{Quantification of spine morphology and density in Gad67-GFP/t-PA ${ }^{-/-}$mice}

A fine network of secondary and tertiary dendrites was acquired from Gad67-GFP/t-PA ${ }^{\mathrm{WT}}$ and double transgenic Gad67-GFP/t-PA ${ }^{-1-}$ mice using a Leica TCS SP2 AOBS confocal laser scanning imaging system (Leica Microsystems AG). Z-stack series of images were later deconvolved using AutoQuant $\mathrm{X}_{3}$ software and loaded into IMARIS imaging software (Bitplane, Zurich, Switzerland) for 3D reconstruction. The Filament Tracer function was used to assign and classify spines, thus yielding spine density and spine categories (stubby, filopodia-shaped, or mushroomshaped). For a given slice, two ROIs were defined, two-tothree dendrites were quantified per ROI, and the total number of quantified neuritis was fixed at 40 per group.

\section{Quantification of tangential and radial migration}

Brain slices from P2 neonates were previously stained by isolectin-B4-TRITC to localize the vascular network of the pial migratory route. To label cortical cells, slices were incubated for $5 \mathrm{~min}$ in $10 \mu \mathrm{M}$ Cell Tracker Green (CTG; Invitrogen) added to the culture medium. The chemically defined culture medium was composed of DMEM/Ham's F12 with $1 \%$ N2 supplement and $1 \%$ antibiotic-antimycotic solution (Sigma-Aldrich). Slices were subsequently washed with culture medium, placed onto a polyester membrane insert from a 6 -well plate, and incubated in a $5 \% \mathrm{CO}_{2}$ atmosphere. After labeling, slices were transferred to an incubator attached to the stand of a confocal macroscope (TCS LSI; Leica Microsystems). The temperature of the chamber was kept at $37.0 \pm 0.5^{\circ} \mathrm{C}$ using a temperature controller (Tempcontrol 37-2 digital 2-channel; PeCon, Ulm, Germany), and the slices were supplied with a constant gas flow $\left(95 \% \mathrm{O}_{2}\right.$, $5 \% \mathrm{CO}_{2} ; \mathrm{CO}_{2}$ controller; PeCon). To visualize cell migration in the tissue slices, the preparation was illuminated with a 488-nm wavelength light by means of a laser diode through a confocal laser scanning macroscope equipped with $\mathrm{a} \times 2$ dry objective (working distance, $39 \mathrm{~mm}$; diameter, $58 \mathrm{~mm}$; Leica Microsystems). Fluorescence emission was detected from 500 to $530 \mathrm{~nm}$. To finely resolve the movement of interneurons, images were acquired with an additional optical zoom factor of 1.5-2.0. Images were collected every $30 \mathrm{~min}$ for up to $6 \mathrm{~h}$. Tracking maps were designed using Metamorph and ImageJ (NIH) upgraded with the tracking plug-in allowing access to the total distance covered and maximal speed parameters [30].

\section{Quantification of locomotor activity of t-PA ${ }^{-/-}$mice}

Locomotor activity of P15 WT and $\mathrm{t}-\mathrm{PA}^{-1-}$ mice was assessed using a Versamax 4.2 apparatus (Accuscan
Instruments Inc., Columbus, OH, USA) and the behavioral analysis platform of the Institute of Research and Innovation in Biomedicine (IRIB; Normandy University). This motor behavioral test was chosen, because morphometric, mechanistic, and functional studies were performed in the sensorimotor prefrontal cortex, and previous studies reported that alteration of the GABAergic system in the prefrontal cortex is associated with locomotor activity impairments [31]. Animals were isolated for $30 \mathrm{~min}$ in individual cages before being placed in individual $20-\mathrm{cm} \times 20-\mathrm{cm} \times 30-\mathrm{cm}$ compartments to limit anxiety in a dark, sound-attenuated, and temperature-regulated $\left(20 \pm 1{ }^{\circ} \mathrm{C}\right)$ room. The test takes advantage of a rodent's natural tendency to explore a new environment. Video-tracking was performed during a 30-min period and analyzed using ANY-maze software (Stoelting, Wood Dale, IL, USA).

\section{In vivo exposure of Gad67-GFP mice to GM6001}

The MMP inhibitor GM6001 (10 mg/kg) was administered daily by subcutaneous injection to pregnant Gad67-GFP mice from E15 to birth and in neonates from birth to P7. The dose of GM6001 administered was based on previous comparative studies that showed that a 10-mg/kg GM6001 subcutaneous injection significantly decreased cortical MMP activity [32]. The control group was treated with $1 \%$ DMSO in PBS. No modification of body weight of pregnant mice was seen in the control and GM6001-treated groups; however, the body weight of pups from the GM6001 group was significantly reduced. After birth, pups were raised until P15 to quantify the density of cortical Gad67-GFP interneurons.

\section{Statistical analysis}

Statistical analyses were performed using the biostatistic Prism software (GraphPad Software, La Jolla, CA, USA). Tests used for each experiment, the number of independent experiments, the number of measures per experiment, and $p$ values are summarized in Table 1. Error bars in the graphs represent SEM.

\section{Results}

\section{Immunohistochemical characterization of the pial migratory route in neonate mice}

Several research groups reported that a significant number of GABA interneurons are still migrating in the superficial cortical layers at birth and during the early postnatal life of both mouse [9] and human [18] neonates. However, most previous studies referring to vessel-associated migration were performed during embryonic stages [11, 33]. Based 


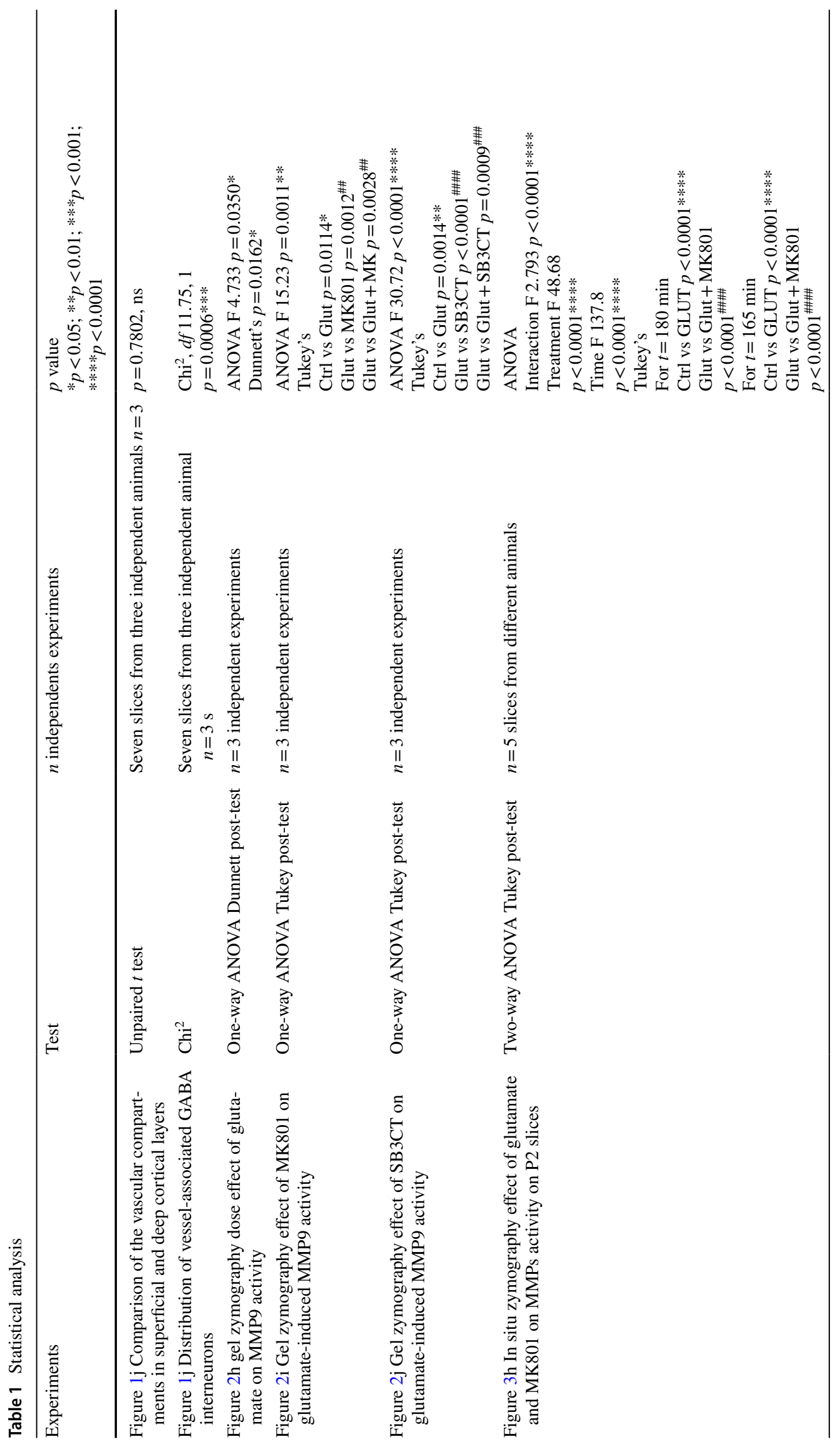




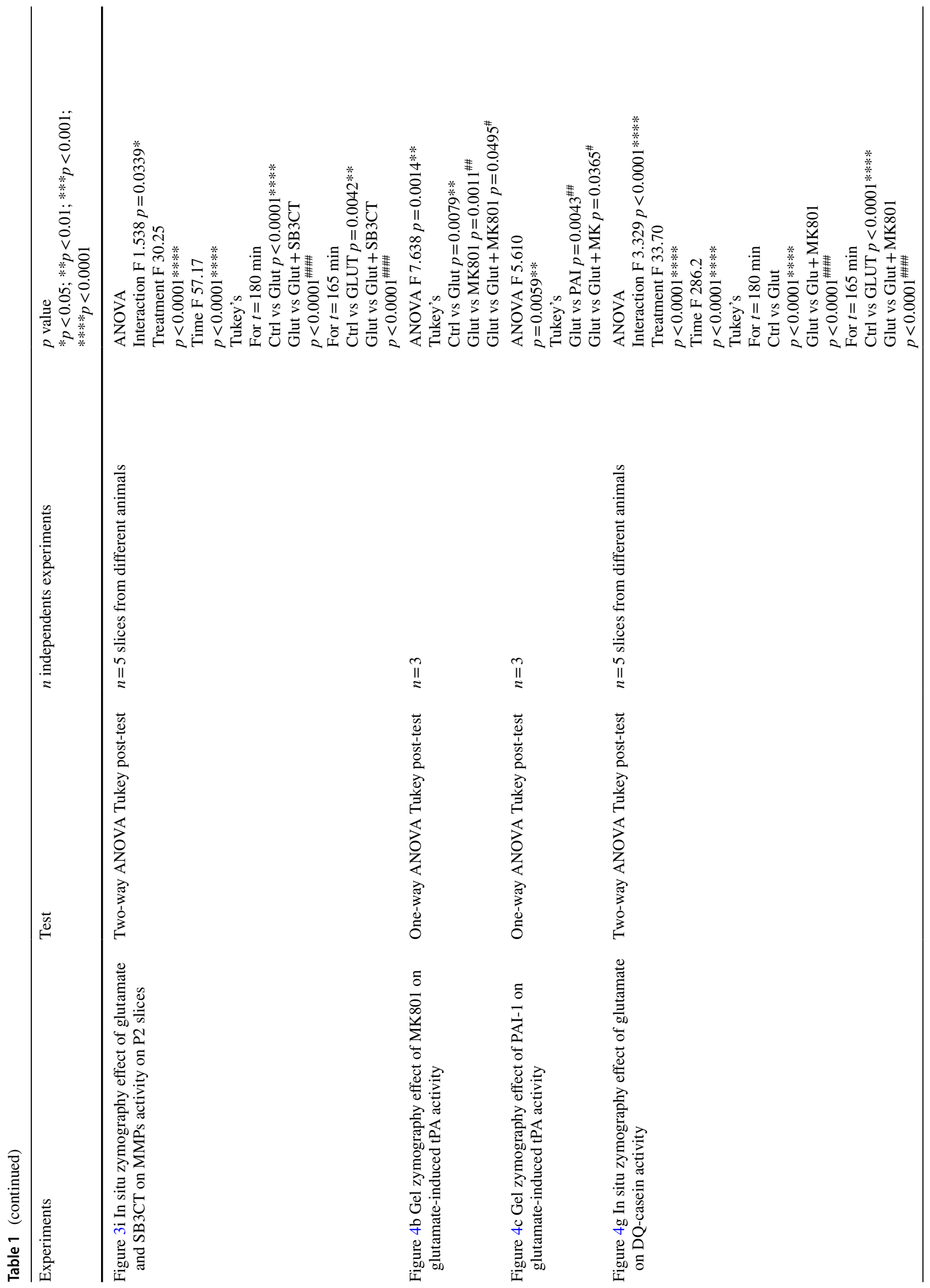




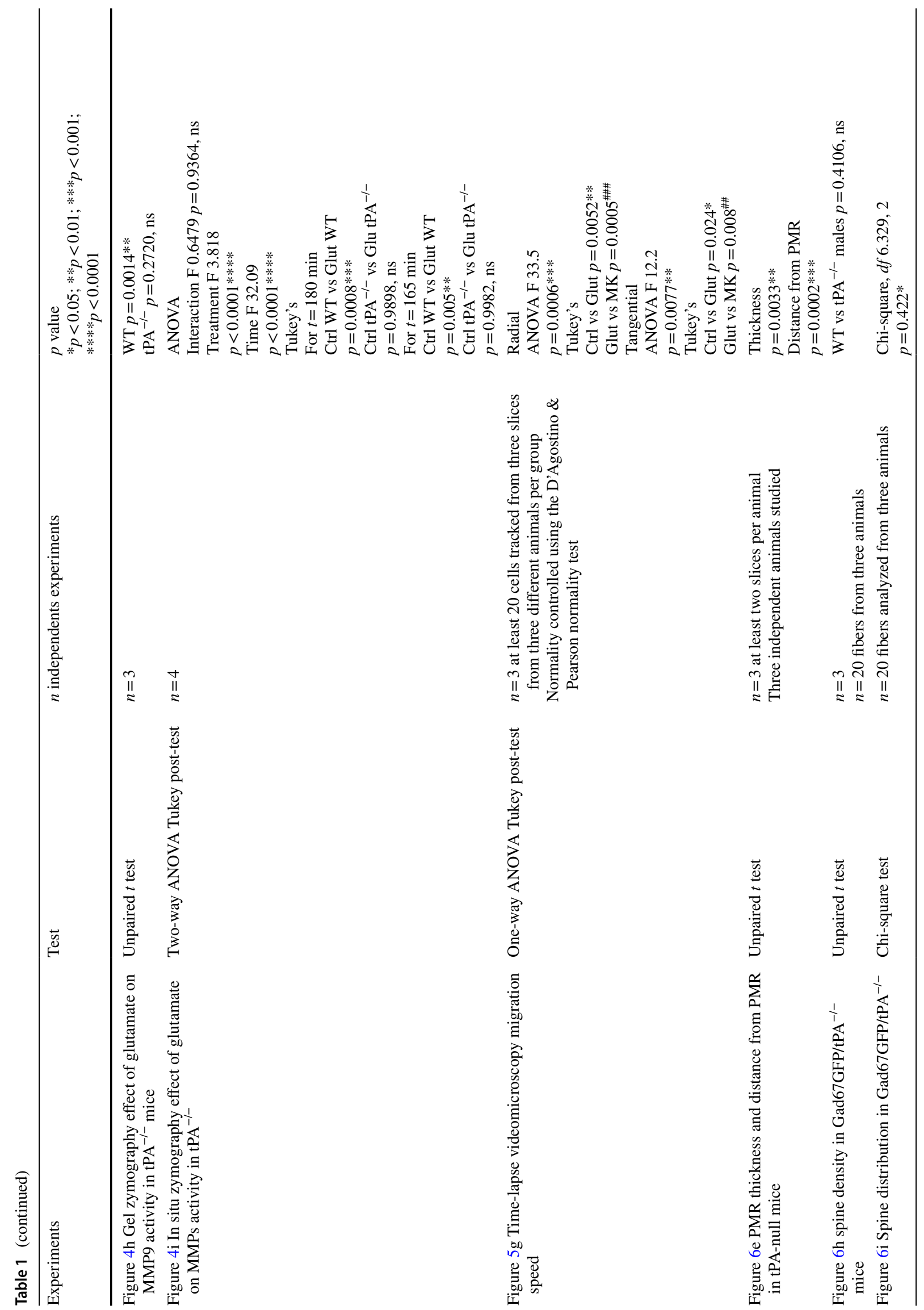




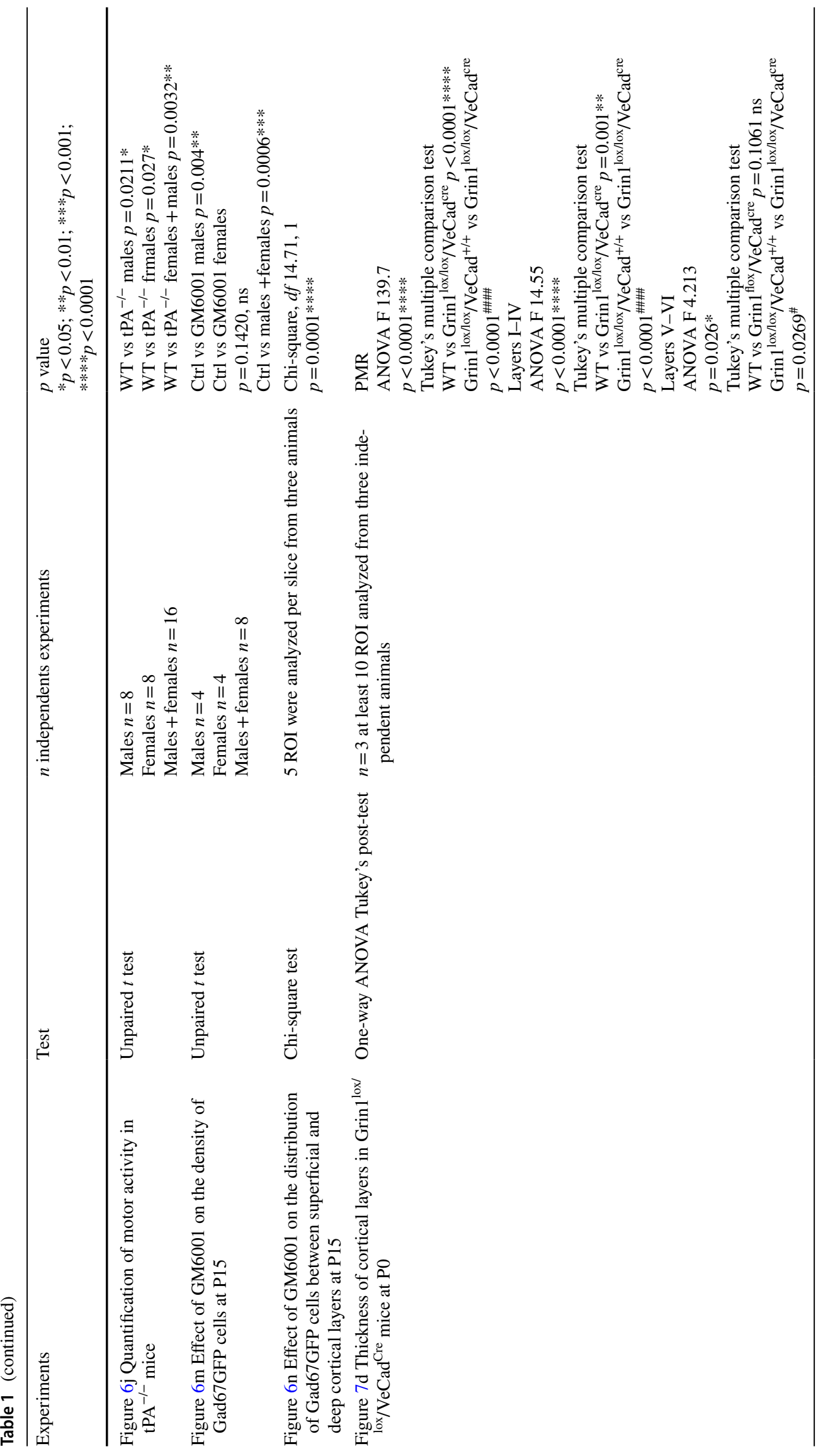




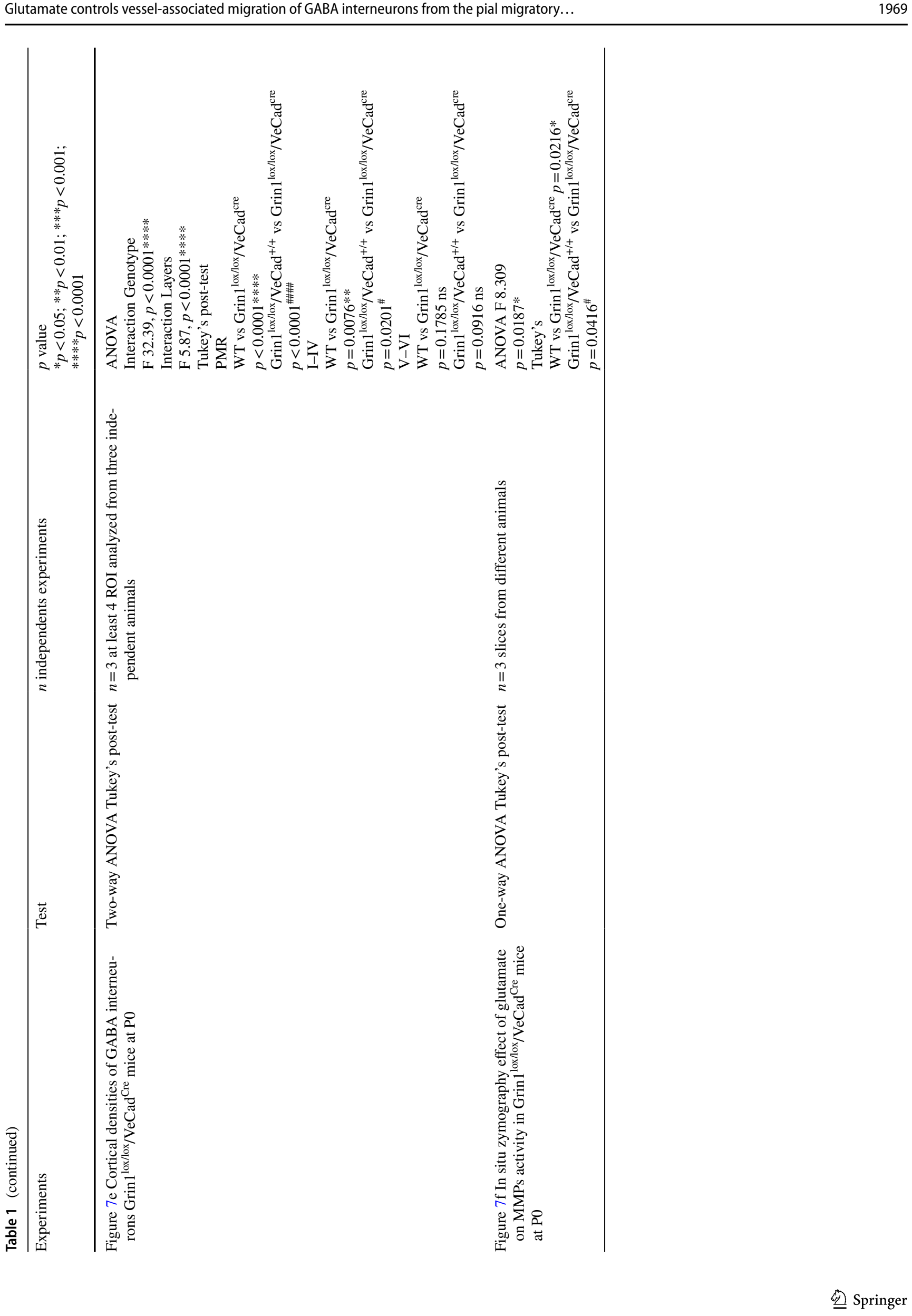




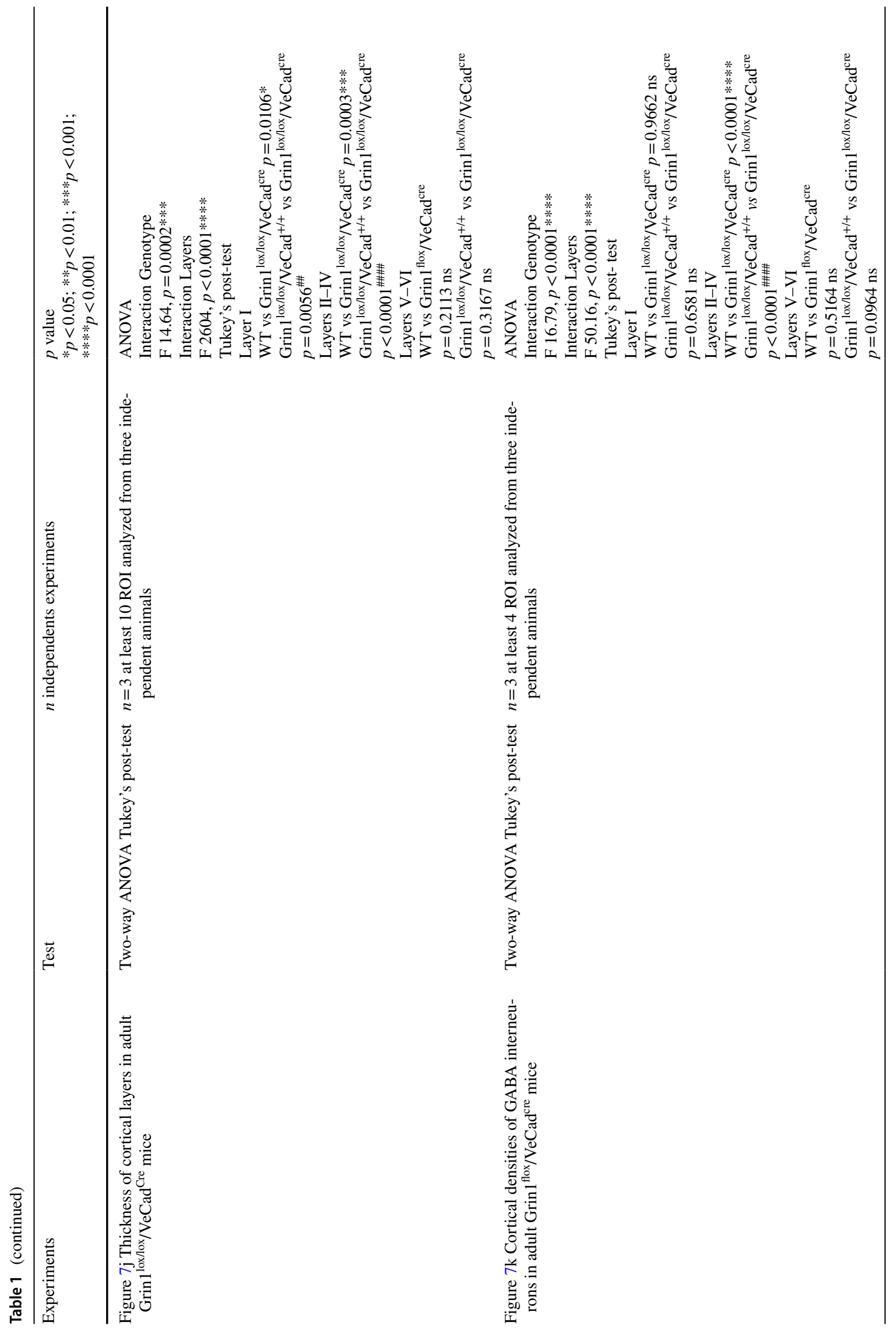


on these statements, we performed immunohistochemistry experiments on the pial migratory route in $\mathrm{P} 2$ neonate mice (Fig. 1). CD31 immunolabeling revealed a thin network of microvessels lining the developing superficial cortical layers (Fig. 1a, b; arrowheads) and radial perforating microvessels (Fig. 1a, b; arrows). Contrasting to the adult cortex used as positive control, immunohistochemistry experiments revealed an absence of Acta2-positive vessels in the developing cortex at $\mathrm{P} 2$, suggesting that the arterial/venous phenotype of radial vessels was not yet fully established at this developmental stage (Supplementary Fig. 3a-e; [61]). Co-labeling experiments using CD31 and GFAP antibodies revealed a row of astrocytes with radial-oriented short processes entering the superficial cortical layers (Supplementary Fig. 4a-c; arrows). DCX immunohistochemistry also showed tangentially oriented cells lining the inner face of the pial migratory route (Supplementary Fig. 4d-f; arrows). At low magnification, confocal acquisitions confirmed the presence of DCX-positive cells lining the PMR and revealed cell clusters stacking at the junction between the PMR and radial cortical microvessels (Fig. 1c, d; arrows). Co-labeled DCXGABA cells with a tangential orientation were observed along the PMR (Fig. 1e) and a line scan analysis of triplelabeled DCX-GABA-CD31 cortical slices showed that both DCX and GABA-immunoreactive profiles overlapped and were localized just below pial vessels (Fig. 1f-h). In the same way, triple immunolabeling targeting CD31, GFAP, and DCX showed that DCX-positive cells were localized just below GFAP-positive cells and pial vessels (Supplementary Fig. 4g-1). In addition, confocal acquisitions at low magnification of double immunolabeling experiments targeting GABA and CD31 clearly showed a preferential while not exclusive association of GABA interneurons with radial microvessels in the superficial cortical layers (Fig. 1i; Supplementary Figs. 2a, c, 3f). Quantitative analysis revealed different "vessel-association" patterns between superficial and deep cortical layers at P2. Indeed, whereas the vessel density was similar between deep and superficial cortical layers, the proportion of interneurons interacting with microvessels appeared significantly more important in the superficial layers of the developing cortex (Fig. 1j). These data indicate that in mouse neonates, late migrating GABA interneurons are interacting with vessels from the pial migratory route and radial microvessels from the superficial cortical layers.

\section{NMDA receptors impact MMP-9 activity in the pial migratory route}

Recent studies showed transcriptomic and proteomic specificities of cortical microvessels in neonate mice [1]. In particular, the expression of NMDA receptors is exacerbated in neonatal endothelial cells when compared to adults [6]. 

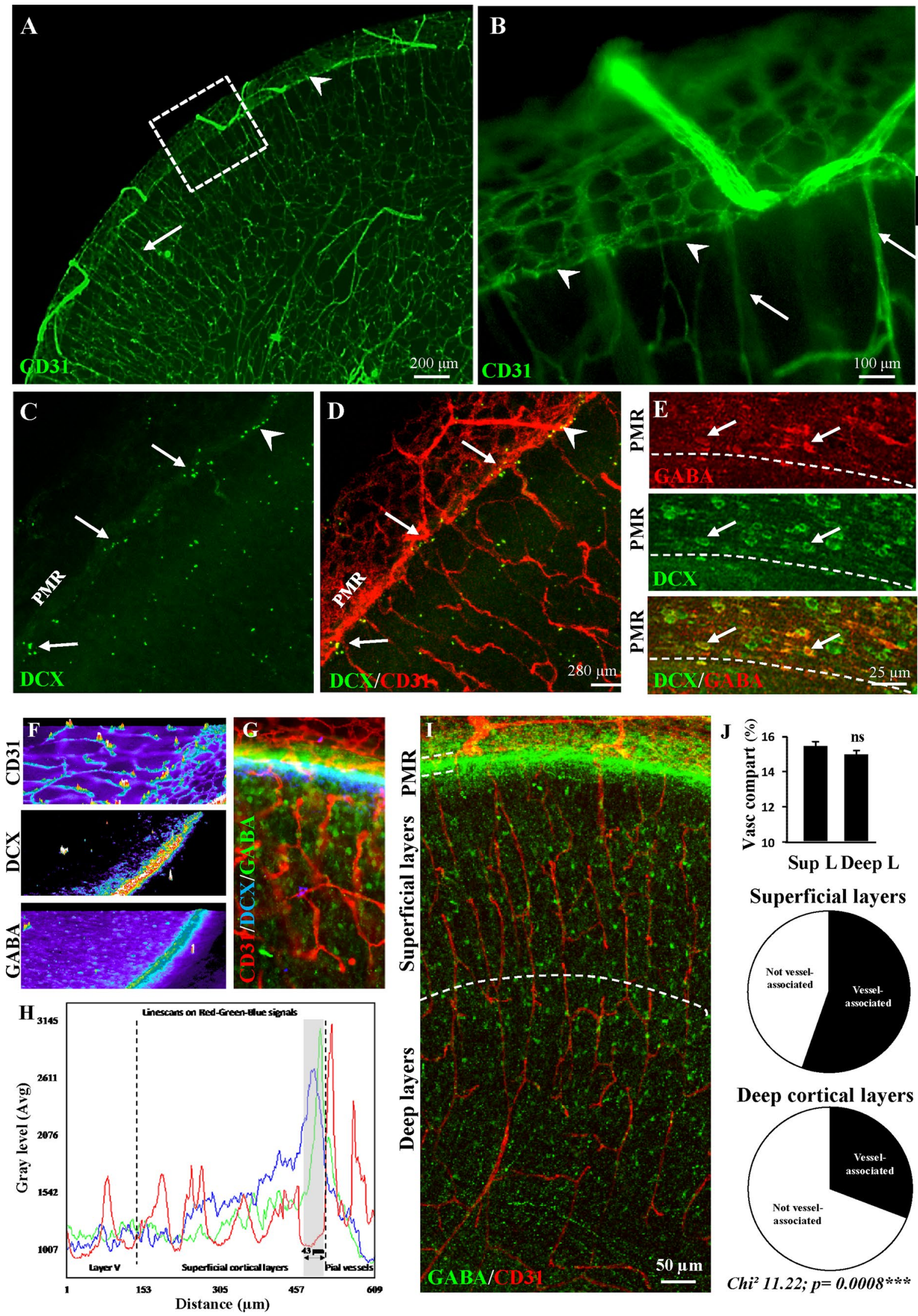

Superficial layers

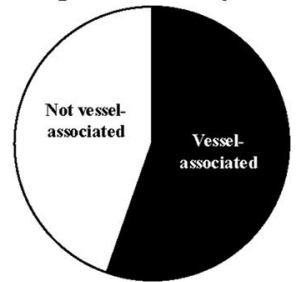

Deep cortical layers

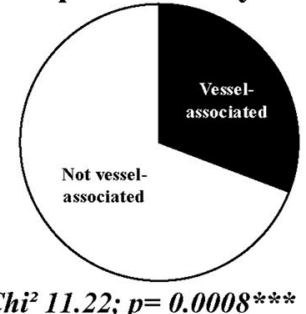


४Fig. 1 Immunohistochemical characterization of the pial migratory route (PMR) in mouse neonates. a, b Low-magnification (a) and high-magnification (b) photographs visualizing cortical microvessels in transversal cortical slices labeled with CD31 antibodies at P2. Arrow heads indicate a thin network of vessels at the level of the PMR. Arrows indicate cortical radial microvessels. c, d Double immunolabeling experiments showing a low-magnification DCXpositive cells (c) lining the PMR (d; arrowhead). Arrows indicate DCX-positive cells stacking at the level of radial microvessels arising from the PMR. e Double immunolabeling experiments showing at high-magnification tangential cells along the PMR immunoreactive for DCX and GABA (arrows). $\mathbf{f}-\mathbf{h}$ Line scan analysis (f) of the CD31 (red), DCX (blue) and GABA (green) fluorescent signals acquired from a cultured brain slice at P2 (g). Intensity profiles (h) indicate that DCX and GABA immunofluorescences overlap and border the inner part of pial vessels. i Confocal acquisition of GABA-immunoreactive cells and CD31-labeled microvessels in the developing neocortex at P2. Note a marked vascular interaction of GABA interneurons along radial microvessels. $\mathbf{j}$ Quantification of vessel density (upper panel) and vessel-associated GABAergic interneurons in the superficial (middle) and deep (lower panel) cortical layers at P2. Note that the vessel association is preferentially observed in the developing superficial layers. $n s$ not statistically different vs superficial layers. The tests used for the statistical analysis, the number of independent experiments, the number of measures per experiment, and $p$ values are detailed in Table 1

However, the distribution pattern of endothelial NMDA receptors in the developing cortex and the possible interactions with the pial migratory route was unknown. GluN1 immunohistochemistry experiments performed on P2 cortices showed intense immunolabeling in radial glia with numerous terminal processes ending at the level of the pial migratory route (Fig. 2a; arrows). GluN1 immunoreactivity was also detected in endothelial cells from the pial migratory route as well as in radial microvessels (Fig. 2b-d; arrowheads). Quantification of the GluN1 mRNA expression by qRT-PCR after laser capture revealed no significant difference between the pial, subpial, and deep microdissected microvessels (Supplementary Fig. 1f). Although MMP-9 is well known to contribute to the pathophysiology of several diseases involving dysfunction of the neurovascular unit during stroke [34] or dysregulation of cell migration with cancers [35], the contribution of MMP-9 to the control of vasculo-associated neuronal migration has never been investigated. Immunohistochemistry showed strong MMP-9 labeling at the level of the pial migratory route (Fig. 2e-g). Interestingly, MMP-9 immunolabeling was preferentially localized in the inner face of the pial vessels where migrating GABA interneurons are observed (Fig. 2e-g; arrows). Gel zymography experiments performed with P2 cultured cortical extracts showed that glutamate induces a concentration-dependent increase of MMP-9 activity $(p<0.05$; Fig. 2h). The glutamate-induced increase of MMP-9 activity was abolished by the NMDA receptor antagonist MK801 $(20 \mu \mathrm{M} ; p<0.01$; Fig. $2 \mathrm{i})$ and by the MMP-9 inhibitor SB$3 \mathrm{CT}(10 \mu \mathrm{M} ; p<0.001$; Fig. $2 \mathrm{j})$.
Because gel zymography performed on $\mathrm{P} 2$ cortical extracts provided data regarding MMP-9 activity but gave no information regarding histological localization, we also performed real time in situ zymography for cultured P2 cortical slices using DQ-gelatin-FITC (Fig. 3a-g). Co-labeling of cortical microvessels with isolectin-B4-TRITC revealed that gelatinase activity was predominantly vascular and detected in the pial vessels (Fig. 3a-c). Time-lapse acquisition also showed gelatinase activity in radial microvessels restricted to the superficial cortical layers (Fig. 3f, g; arrows). Quantification of the gelatinase activity showed that glutamate $(100 \mu \mathrm{M})$ induces significant $(p<0.0001)$ and time-dependent increases of DQ-gelatin-FITC proteolysis (Fig. 3h). This effect was abrogated by MK801 (20 $\mathrm{MM}$; Fig. 3h) as well as by SB-3CT ( $10 \mu \mathrm{M}$; Fig. 3i). These data indicate that in P2 cortical slices, glutamate is able to stimulate MMP-9 activity in vessels from the pial migratory route through an NMDA receptor-dependent mechanism.

\section{Glutamate controls t-PA activity in the pial migratory route}

Previous studies have reported that t-PA is able to promote MMP-9 activation in a pathological context [36], whereas other research groups mentioned delayed neuronal migration in t-PA ${ }^{-/-}$mice [37]. Considering this literature, it was tempting to speculate the contribution of t-PA to the control of MMP-9 activity in the pial migratory route. Immunohistochemistry experiments revealed intense t-PA labeling in both the pial and radial microvessels entering the superficial cortical layers (Fig. 4a; arrows). In addition, gel zymography experiments indicated that 6 -h incubation of cultured P2 cortical slices with glutamate $(100 \mu \mathrm{M})$ induces a significant increase in t-PA activity ( $p<0.01 ;$ Fig. 4 b). This effect was blocked by MK801 (20 $\mu \mathrm{M} ; p<0.05$; Fig. 4b) and the t-PA inhibitor PAI-1 ( $5 \mathrm{nM} ; p<0.05$; Fig. 4c). Real-time in situ zymography performed on $\mathrm{P} 2$ cortical slices using DQ-casein-FITC showed that protease activity was localized in vessels bordering the pial migratory route (arrowheads) as well as in cortical radial microvessels (Fig. 4d-f; arrows). Quantification indicated that glutamate $(100 \mu \mathrm{M})$ induced a time-dependent and significant increase of the DQ-caseinFITC proteolysis $(p<0.0001$; Fig. $4 \mathrm{~g})$. This effect of glutamate was abrogated by MK801 $(p<0.0001$; Fig. 4 g). In addition, gel and in situ zymography revealed that treatment of $\mathrm{P} 2$ cortical slices from t-PA ${ }^{-/-}$mice with glutamate $(100 \mu \mathrm{M})$ failed to stimulate MMP-9 activity (Fig. 4h, i; Supplementary Fig. 5c, h). These data indicate that glutamate is able to stimulate t-PA activity in vessels from the pial migratory route through a NMDA receptor-dependent mechanism and that glutamate-induced MMP-9 activation is t-PA-dependent. 
Fig. 2 GluN1 immunoreactivity in microvessels from the pial migratory route (PMR) and glutamate-dependent regulation of MMP-9 activity. a-d Double immunolabeling experiments showing CD31-positive microvessels and GluN1 immunoreactivity in the neocortex of $\mathrm{P} 2$ mice. Immunohistochemistry reveals numerous GluN1-positive cortical radial fibers (a; arrows) and GluN1-positive endothelial cells in the pial migratory route (b-d; arrowheads). e-g Double immunolabeling experiments showing CD31-positive microvessels (e) and MMP-9 immunoreactivity (f) in vessels from the pial migratory route. The overlay (g) indicates that MMP-9 immunoreactivity mainly co-localizes with endothelial cells present in the inner part of the migratory route (arrows). h Quantification by gel zymography of the effects of 6-h exposure of P2 cortical slices to graded concentrations $(25-100 \mu \mathrm{M})$ of glutamate on MMP-9 activity. i Quantification by gel zymography of the effect of the NMDA-antagonist MK801 $(20 \mu \mathrm{M})$ on the glutamateinduced increase of MMP-9 activity. j Quantification by gel zymography of the effect of the MMP-9 inhibitor SB-3CT $(10 \mu \mathrm{M})$ on the glutamateinduced increase of MMP-9 activity. $* p<0.05 ; * * p<0.01$ vs control and ${ }^{\# \#} p<0.01$; \#\#\# < 0.001; \#\#\# $\mathrm{p}<0.0001$ vs glutamate. The tests used for the statistical analysis, the number of independent experiments, the number of measures per experiment, and $p$ values are detailed in Table 1

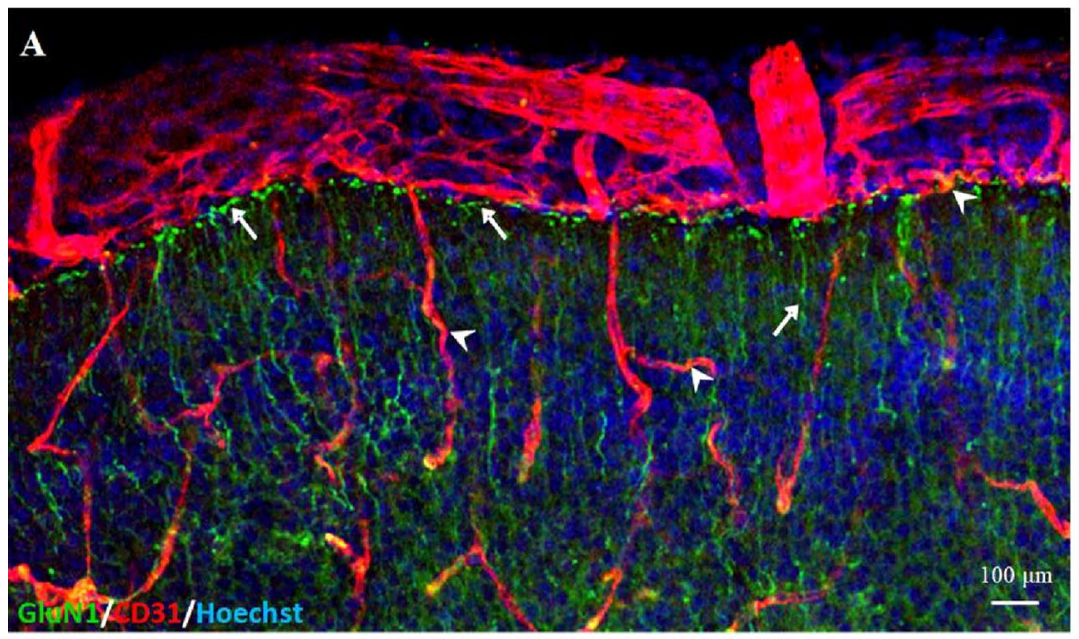

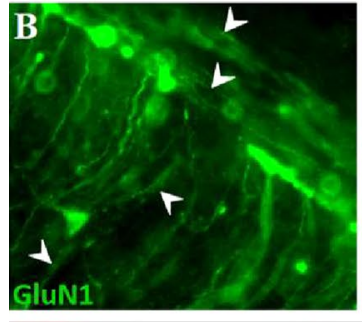
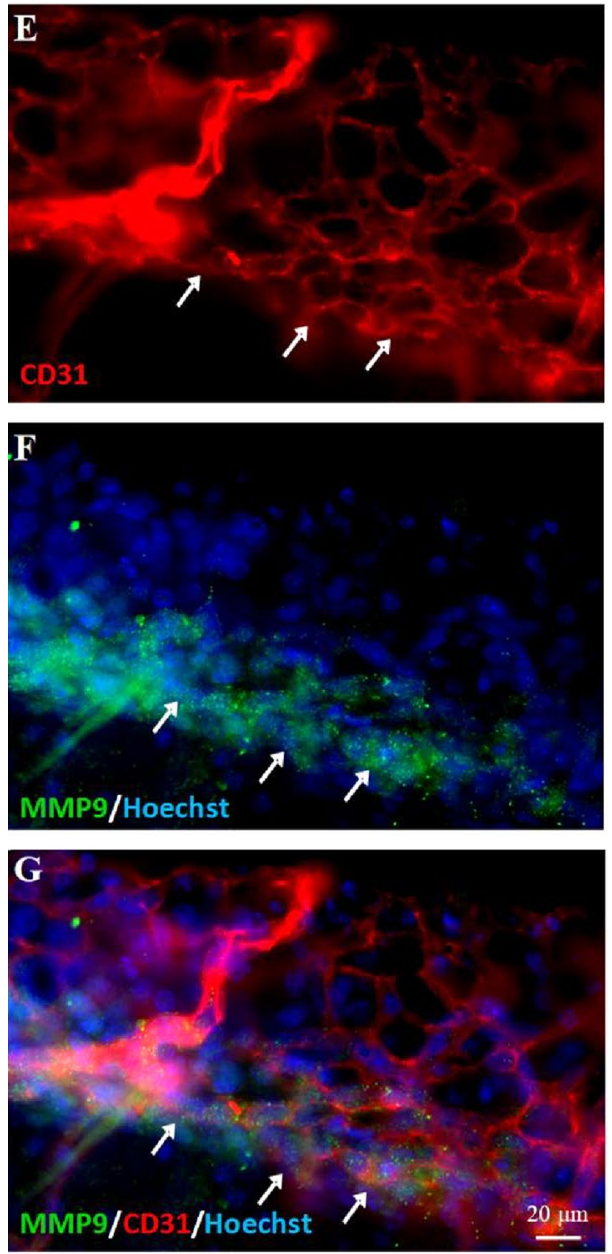
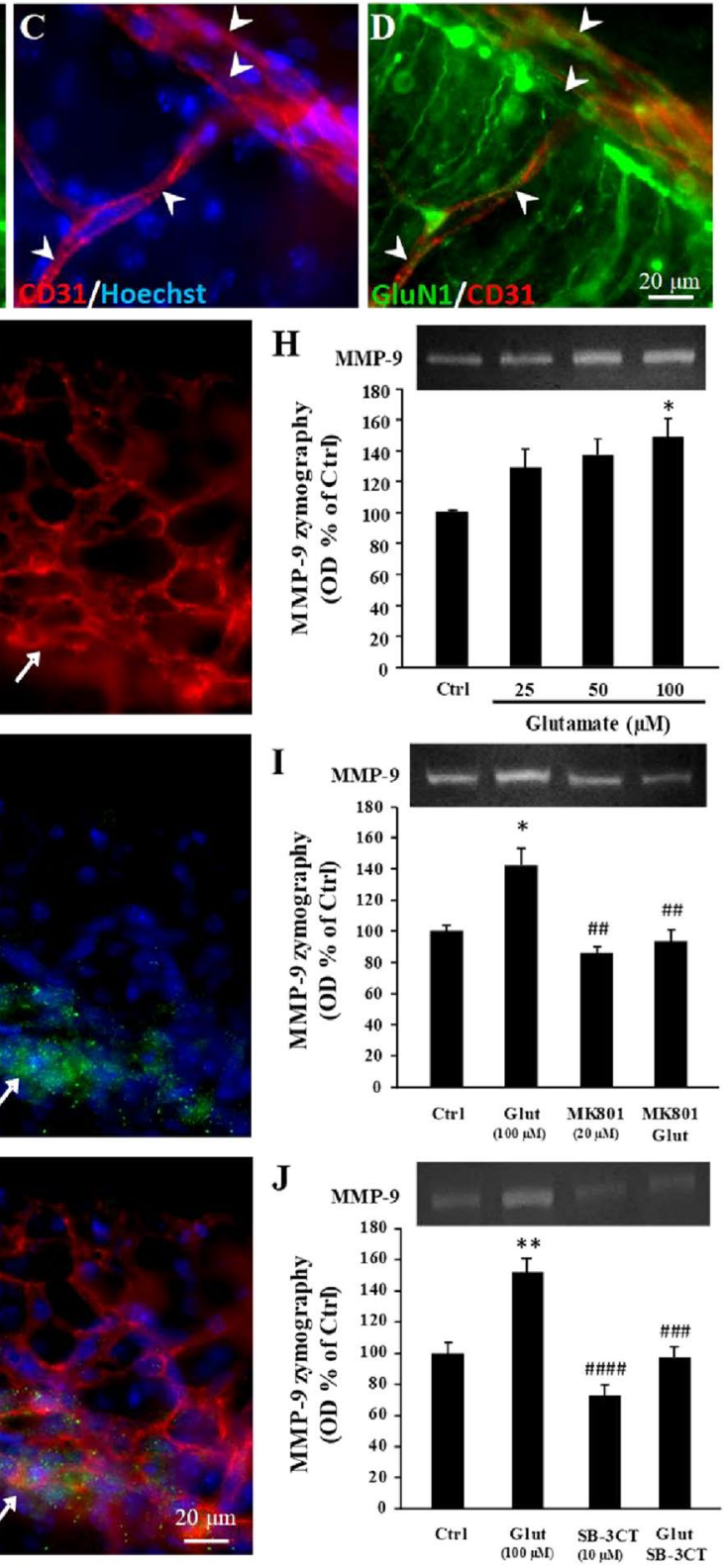


\section{Glutamate controls vascular-associated migration of GABA interneurons in the pial migratory route}

Because t-PA and MMP-9 are involved in the remodeling of the extracellular matrix following ischemic stroke [38], and because the present study revealed NMDA-dependent effects of glutamate on the endothelial activity of these two proteases, we hypothesized that glutamate could regulate the vascular-associated migration of GABA interneurons along the pial migratory route. Gad67-GFP mice whose neurons are known to populate the superficial cortical layers (Supplementary Fig. 6; [25]) confirmed the preferential association with microvessels at P2 (Fig. 5a). To investigate the effects of glutamate on the migration of GABAergic cells along the PMR and radial vessels, we performed time-lapse acquisitions using a confocal laser scanning macroscope (Fig. 5b-g). Time-lapse acquisitions revealed several cells migrating in an outside-in direction in close interaction with microvessels (Fig. 5b-e; arrows; Supplementary video). Some cells close to microvessels covered up to $40 \mu \mathrm{m}$ of distances during the first $6 \mathrm{~h}$ of recording (Fig. $5 \mathrm{f}$ ). The addition of glutamate $(50 \mu \mathrm{M})$ to the culture medium significantly increased the maximal speed of both tangential and radial migrating cells $(p<0.01$; Fig. $5 \mathrm{~g})$. In contrast, incubation of the slices with MK801 $(20 \mu \mathrm{M})$ reduced cell migration $(p<0.001$; Fig. $5 \mathrm{~g})$. These data indicate that in neonates, glutamate stimulates the vascular-associated migration of GABA interneurons through a NMDA receptor-dependent mechanism.

\section{t-PA invalidation and in vivo MMP inhibition impair the integration of GABA interneurons migrating via the pial migratory route}

To research developmental consequences of the impairment of t-PA and MMP activities characterized in pial and radial microvessels during perinatal life, we performed histological and behavioral studies in t-PA ${ }^{-/-}$and double transgenic Gad67-GFP/t-PA ${ }^{-1-}$ mice (Fig. 6). Double immunolabeling experiments targeting GABA and CD31 revealed a marked reduction of the PMR thickness in $\mathrm{P} 2 \mathrm{t}-\mathrm{PA}^{-/-}$mice $(p<0.01$; Fig. 6a-e). In addition, immunohistochemistry showed that, in $\mathrm{t}-\mathrm{PA}^{-1-}$ mice, the distance of GABA interneurons from the PMR was significantly reduced ( $p<0.001$; Fig. 6a-e). Because a major phase of elimination/maturation of the GABAergic neurons has been described during the first 2 weeks postnatally [39], we investigated spine morphology of Gad67-GFP neurons at P15. Confocal microscopy acquisition in superficial layers II-IV of P15 Gad67-GFP/t-PA ${ }^{\text {wt }}$ revealed several GABAergic neurons with dendritic spines (Fig. 6f). The 3D image analysis with the Imaris Filament tracer application allowed discrimination of three subtypes of spines (mushrooms, filopodia, and stubbies; Fig. $6 \mathrm{~g}$ ).
Quantification showed no significant differences in spine density between Gad67-GFP/t-PA ${ }^{\text {WT }}$ and Gad67-GFP/t$\mathrm{PA}^{-1-}$ mice (Fig. 6h). In contrast, the distribution of spine subtypes was significantly impaired (Fig. 6i). In particular, the proportion of filopodia was increased in P15 Gad67GFP/t-PA ${ }^{-1-}$ mice $(p<0.05$; Fig. 6i). This effect on Gad67GFP neurons was associated with a decrease of somatostatinergic neurons in the superficial layers of t- $\mathrm{PA}^{-1-}$ mice at P15 (Supplementary Fig. 7). Furthermore, behavioral experiments showed that morphometric and cellular impairments observed in t-PA ${ }^{-1-}$ mice at $\mathrm{P} 15$ were associated with locomotor troubles; indeed, a marked increase in the total distance covered was found in male and female t-PA ${ }^{-/-}$mice at P15 ( $p<0.01$ for females and males; Fig. 6j). Previous reports indicated that in vivo administration of the MMP inhibitor GM6001 was able to impact vascular remodeling in mouse brain [40], and we consequently investigated the effects of a daily injection of GM6001 $(10 \mathrm{mg} / \mathrm{kg})$ during perinatal life in Gad67-GFP mice (Fig. 6k-n). As observed in $\mathrm{t}-\mathrm{PA}^{-/-}$mice, data revealed a marked reduction in the density of Gad67-GFP neurons at P15 in the superficial cortical layers of animals in vivo-exposed to GM6001 during perinatal life $(p<0.001$ for females and males; Fig. 6k-m). In addition, several ectopic cells were observed in deep cortical layers (Fig. 6k, 1, n; arrows). Altogether, these data indicate that impairment of MMP-9 and t-PA affects the positioning of GABAergic interneurons populating the superficial cortical layers and this cellular phenotype is associated with exacerbated locomotor activity in t-PA null mice.

\section{The positioning of GABA interneurons populating the superficial cortical layers is impaired in Grin 1 lox/ ${ }^{\text {lox }} / \mathrm{VeCad}^{\mathrm{Cre}}$ mice}

Previous studies reported the expression of NMDA receptors by migrating GABAergic precursors [41]. To reinforce the demonstration of a direct contribution of the endothelial NMDA receptor on migrating GABA interneurons in the PMR and superficial cortical layers, we used Grin $1^{\text {lox } / l o x /}$ $\mathrm{VeCad}^{\mathrm{Cre}}$ mice. LoxP and Cre recombinase insertions were validated by PCR (Fig. 7a, b), while Grin1 inactivation was validated by qRT-PCR from purified cortical microvessel preparations (Supplementary Fig. 9). Major phenotypic abnormalities were observed regarding the positioning of GABA interneurons at two developmental stages. At birth, the thickness of the PMR was strongly reduced in Grin $1^{\text {lox/lox/ }}$ VeCad ${ }^{C r e}$ mice when compared to Grin $1^{+/+} / \mathrm{VeCad}^{+/+}$(wildtype) and Grin $1^{l o x / l o x} / \mathrm{VeCad}^{+/+}$mice $(p<0.0001$; Fig. $7 \mathrm{c}$, d). This effect was associated with a significant decrease of the GABA interneuron density in the developing superficial layers ( $p<0.0001 ;$ Fig. 7 c, e). Moreover, in situ zymography experiments showed a significant decrease of the glutamateinduced MMP-like activity along the PMR $(p<0.05$; Fig. $7 \mathrm{f}$ 
Fig. 3 In situ characterization of the effects of glutamate on MMP activity in vessels from the pial migratory route. a-c In situ zymography performed for P2 cortical slices visualizing the MMP gelatinase activity in control conditions after 60-min incubation with the quenched fluorogenic substrate DQ-gelatin-FITC. Note that the gelatinase activity (a) overlaps with microvessels present in the pial migratory route labeled with isolectin-TRITC (b, c). d-g Microphotographs acquired by videomicroscopy show a time-dependent increase of the gelatinase activity in cultured slices incubated with glutamate $(100 \mu \mathrm{M})$ from 0 to $90 \mathrm{~min}$. Note that in addition to the PMR (arrowheads), a fluorescent signal also progressively appeared in radial cortical vessels (arrows; $\mathbf{f}, \mathbf{g}$ ). h Time-lapse quantification by videomicroscopy of the fluorescence intensity resulting from DQ-gelatinFITC cleavage after treatment of brain slices with aCSF (Ctrl), glutamate $(100 \mu \mathrm{M})$, and the NMDA-antagonist MK801 $(20 \mu \mathrm{M})$ alone or co-incubated (h). i Quantification by videomicroscopy of the fluorescence intensity resulting from DQ-gelatin-FITC cleavage after treatment of brain slices with aCSF (Ctrl), glutamate $(100 \mu \mathrm{M})$, and the MMP2/9 inhibitor SB-3CT $(10 \mu \mathrm{M})$ alone or co-incubated. Statistical analysis revealed significant Time and Treatment interactions. $* * p<0.01$; *** $p<0.001$; $* * * * p<0.0001$ vs control at the same time point and \#\#\#\# $p<0.0001$ vs glutamate at the same time point. The tests used for the statistical analysis, the number of independent experiments, the number of measures per experiment, and $p$ values are detailed in Table 1
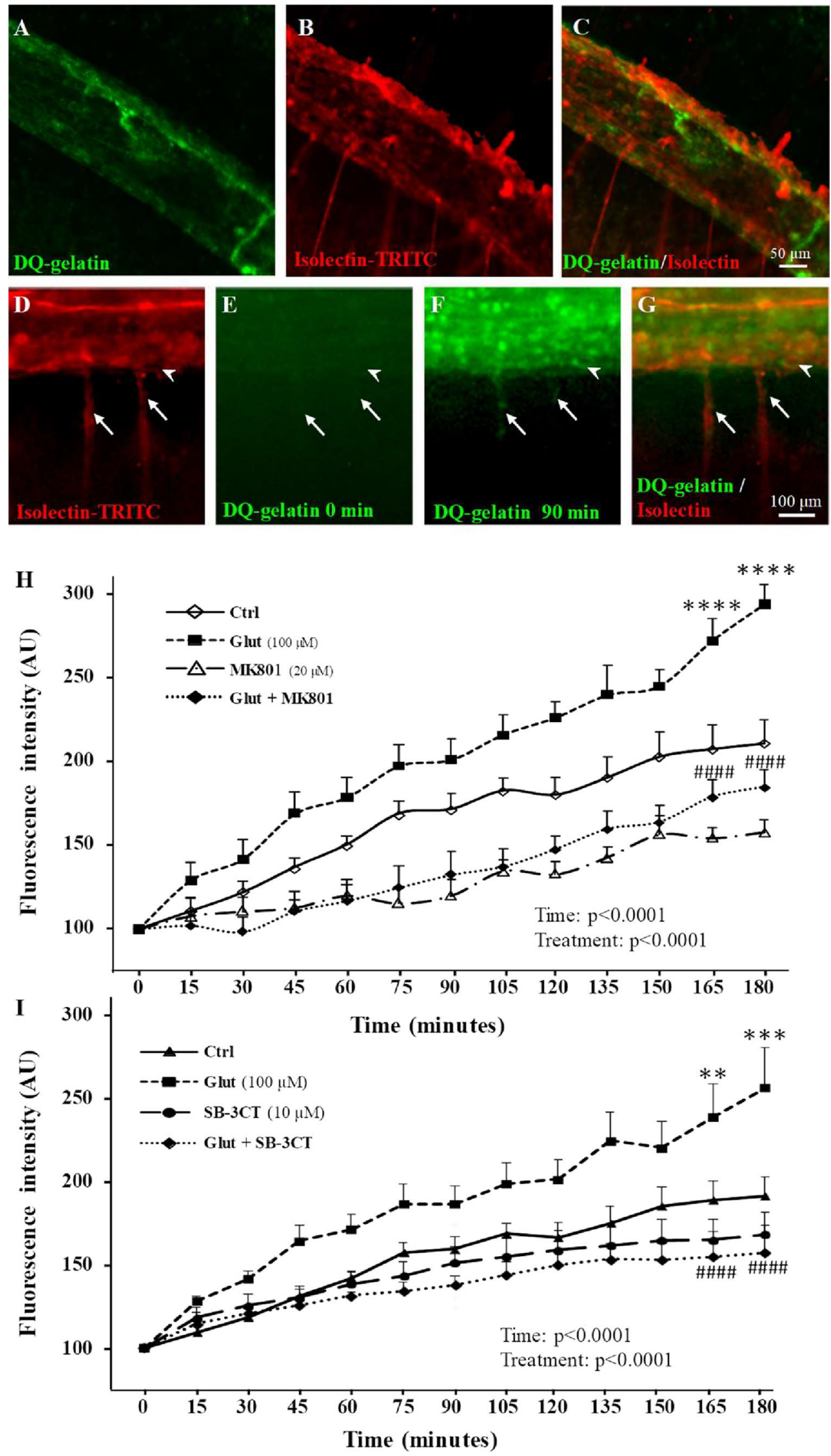

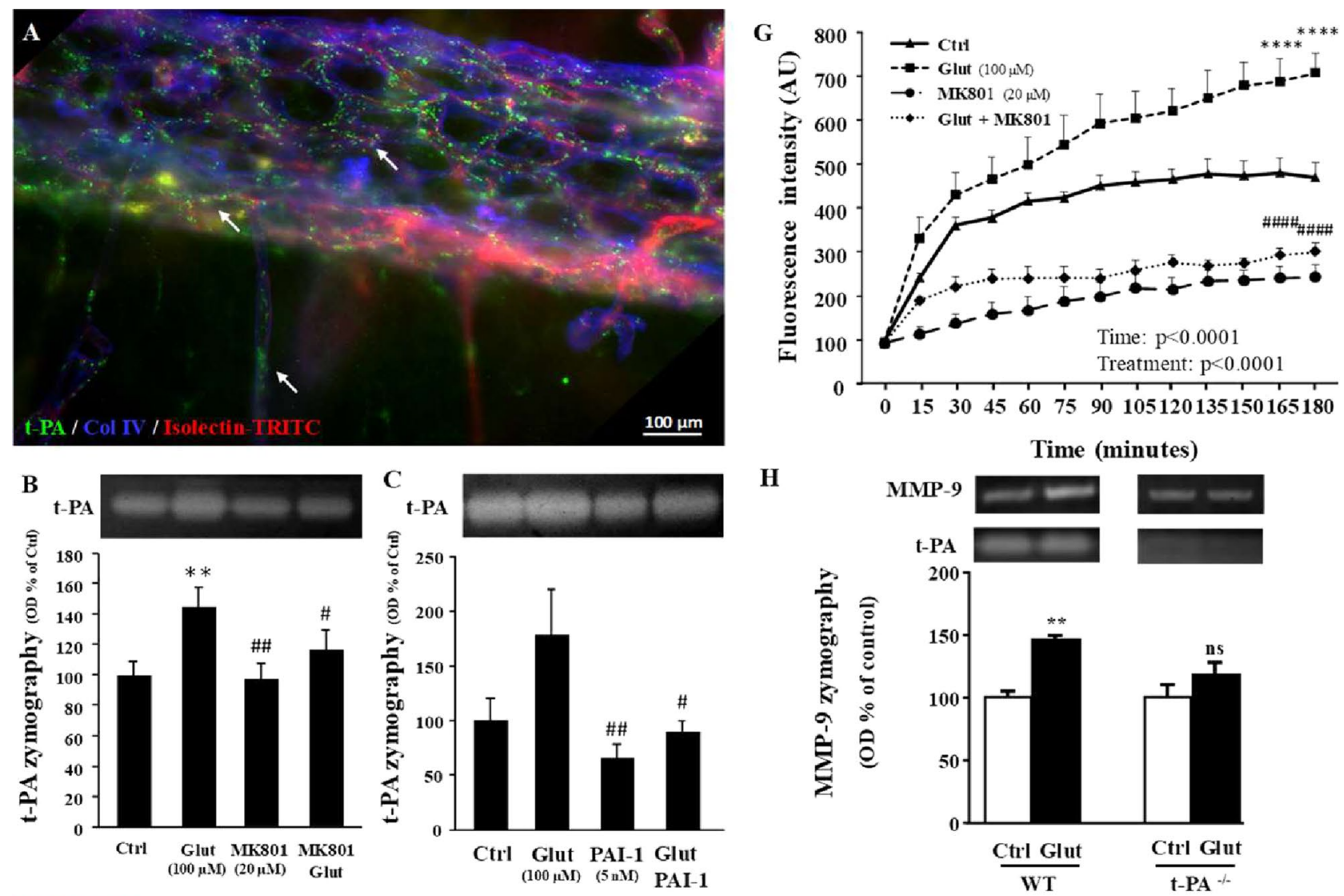

$\mathbf{H}$

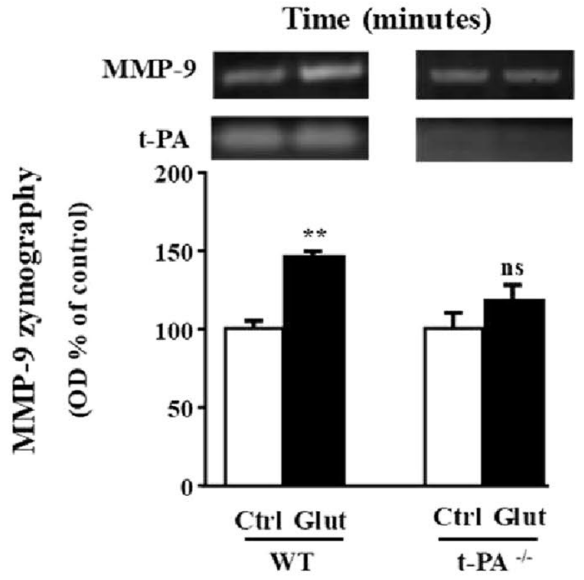

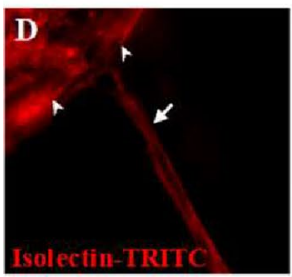
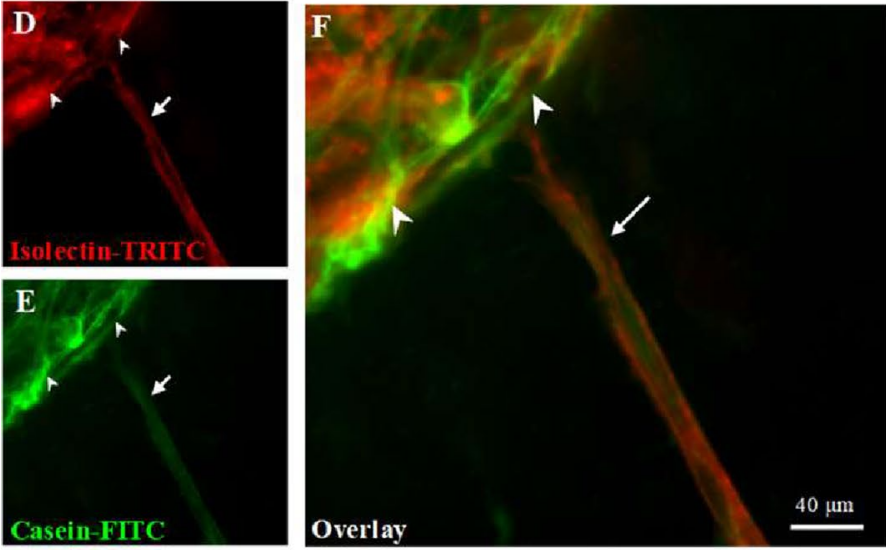

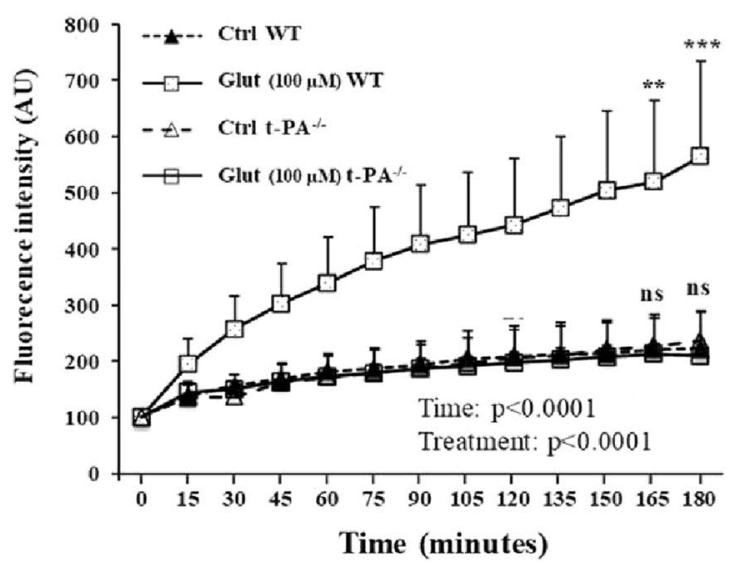

Fig. 4 Visualization and quantification of the effects of glutamate on t-PA activity in vessels from the pial migratory route. a Triple labeling visualizing t-PA, collagen IV, and microvessels in the pial migratory route. Note the presence of strong vascular t-PA immunoreactivity in both tangential and radial cortical vessels (arrows). b Quantification by gel zymography of the effects of aCSF (Ctrl), glutamate $(100 \mu \mathrm{M})$, and the NMDA-antagonist MK801 $(20 \mu \mathrm{M})$ alone or co-incubated on t-PA activity after 3-h treatment of P2 cortical slices. c Quantification by gel zymography of the effects of aCSF (Ctrl), glutamate $(100 \mu \mathrm{M})$, and the t-PA inhibitor PAI-1 $(5 \mu \mathrm{g} / \mathrm{mL})$ alone or co-incubated on t-PA activity after 3-h treatment of P2 cortical slices. d-f Microphotographs acquired by in situ zymography and visualizing cortical microvessels (d) and the fluorescent signal resulting from the cleavage of the quenched casein-FITC substrate (e) in cultured P2 cortical slices. Overlay reveals a strong protease activity associated with the pial migratory route (arrowheads) and radial cortical microvessels (arrows, $\mathbf{f}$ ). g Quantification by time-lapse videomicroscopy of the fluorescence intensity resulting in casein-FITC cleavage after incubation of P2 brain slices with aCSF (Ctrl), glutamate $(100 \mu \mathrm{M})$, and MK801 $(20 \mu \mathrm{M})$ alone or co-incubated. h Quantification by gel zymography of the effects of glutamate $(100 \mu \mathrm{M})$ on MMP-9 activity in P2 cortical extracts from wild-type (WT) and $\mathrm{t}_{-} \mathrm{PA}^{-/-}$mice. i Quantification by in situ zymography of the effects of glutamate $(100 \mu \mathrm{M})$ on the cleavage of the quenched casein-FITC substrate in WT and t-PA ${ }^{-1-}$ mice at the level of the pial migratory route in P2 cortical slices. Statistical analysis revealed significant Time and Treatment interactions. ns not significant; $* * p<0.01$;

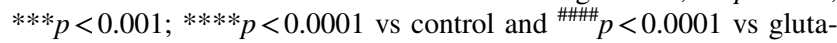
mate. The tests used for the statistical analysis, the number of independent experiments, the number of cells tracked per experiment, and $p$ values are detailed in Table 1 

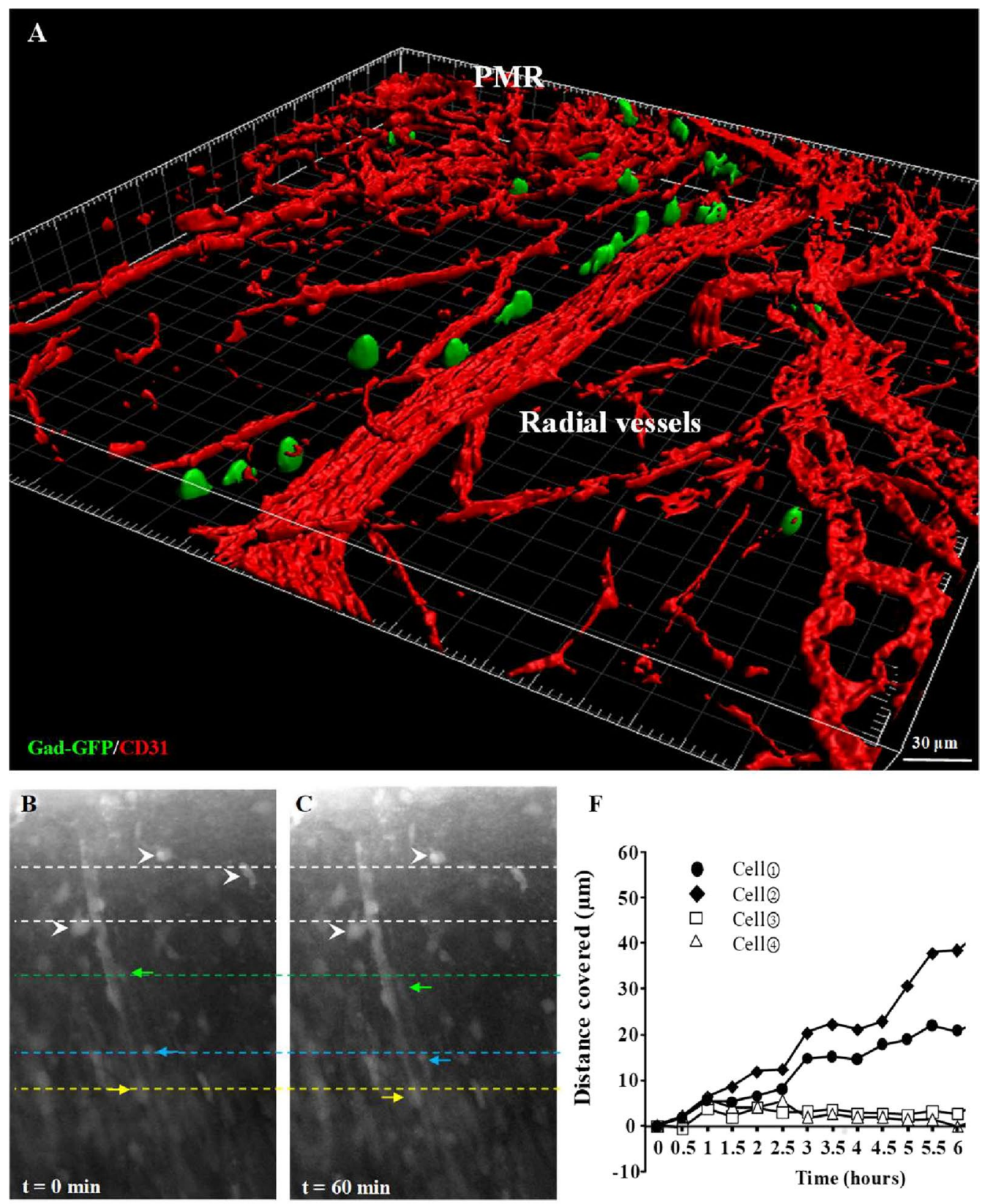

F
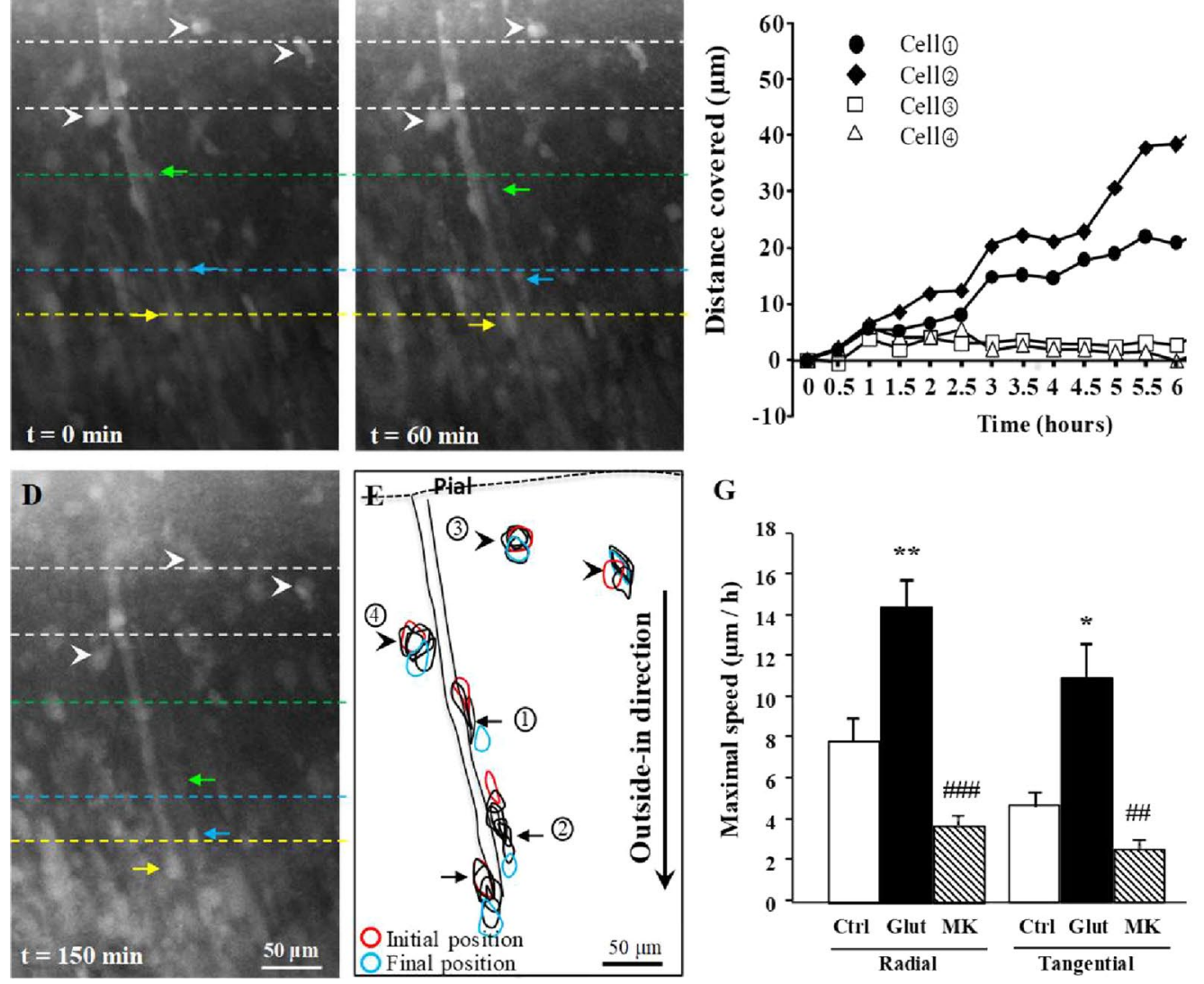
4Fig. 5 Effects of glutamate and MK801 on the vessel-associated migration of GABA interneurons. a 3D Imaris modeling of migrating interneurons along radial microvessels in Gad67-GFP mice at P2. GFP-positive neurons were visualized by immunohistochemistry and microvessels labeled with CD31 antibodies. b-d Microphotographs acquired from the same cultured slice at different times of tracking (0 $\mathrm{min}, \mathbf{b} ; 60 \mathrm{~min}, \mathbf{c}$; and $150 \mathrm{~min}, \mathbf{d}$ ). Arrows indicate migrating cells along microvessels. Arrowheads indicate immobile large cells. e Stacked graph visualizing the position of several cells during 6-h video-tracking. f Quantification of the distance covered by the four cells identified in e. $\mathbf{g}$ Effects of glutamate $(50 \mu \mathrm{M})$ and MK801 $(20 \mu \mathrm{M})$ on the migration speed of cells moving tangentially and radially along microvessels. $* * p<0.01$ vs control and ${ }^{\# \#} p<0.001$ vs glutamate. The tests used for the statistical analysis, the number of independent experiments, the number of measures per experiment, and $p$ values are detailed in Table 1

and Supplementary Fig. 8). Interestingly, an MMP-like activity was observed in nervous cells in $\mathrm{Grin} 1^{\text {lox } / l o x} / \mathrm{VeC}$ $\mathrm{ad}^{\mathrm{Cre}}$ mice (Supplementary Fig. 8; arrowheads). In adults, the cortical positioning of GABA interneurons remained clearly impaired in Grin $1^{\text {lox/lox }} / \mathrm{VeCad}^{\text {Cre }}$ mice (Fig. 7h-i). In particular, a strong depopulation of Gad67-immunoreactive interneurons was observed and quantified in the superficial cortical layers II-IV ( $p<0.0001$; Fig. 7k). Interestingly, ectopic cells were observed in layer $\mathrm{V}$ and the thickness of layer I was significantly increased in $\mathrm{Grin} 1^{l o x} / / 0 x / \mathrm{VeCad}{ }^{C r e}$ mice $(p<0.0001$; Fig. $7 \mathrm{i}, \mathrm{j})$. These results strongly support the contribution of the endothelial NMDA receptor for a correct positioning of GABA interneurons populating the superficial cortical layers.

\section{Discussion}

Literature suggests that exposure of the developing brain to NMDA antagonists during perinatal life is deleterious for the survival of immature GABA interneurons $[13,16$, 17]. In humans, as well as in rodents, numerous GABAergic interneurons are still migrating during late gestation and even after birth $[9,18]$. This process has been shown to be vessel-associated (Fig. 8; [11]). Moreover, in vitro studies revealed age-specific expression of functional NMDA receptors by endothelial cells during perinatal life $[6,42]$ and, interestingly, at a pathological level, several recent studies reported links between NMDA receptor hypofunction during early life and GABA interneurons that could contribute to adult diseases [22-24]. Based on these statements, we hypothesized that glutamate would contribute to the control of the vasculo-associated migration of immature GABA interneurons by modulating the endothelial NMDA receptor.

Using WT and different transgenic (Gad67-GFP, Gad67GFP/t-PA ${ }^{-/-}$, and Grin $1^{l o x} / / 0 x / \mathrm{VeCad}^{\mathrm{Cre}}$ ) mice, highlights of the present study (Fig. 8) are as follows: (1) glutamate induces an NMDA-dependent increase of MMP-9 and t-PA activities in microvessels along the pial migratory route and radial cortical microvessels in superficial layers, (2) there is a strong association of GABA interneurons with radial microvessels in the developing cortical layers, (3) glutamate induces an NMDA-dependent increase of the migration speed of immature GABA interneurons along the pial migratory route and radial cortical vessels, (4) effects of glutamate on MMP-9 activity is t-PA dependent and t-PA invalidation impairs the positioning of GABA interneurons in the superficial cortical layers, and (5) a marked reduction of the glutamate-induced MMP-9 activity is observed along the PMR in Grin $1^{l o x / l o x} / \mathrm{VeCad}^{\mathrm{Cre}}$ and this effect is associated with a depopulation of GABA interneurons in superficial cortical layers.

\section{Glutamate regulates MMP-9 and t-PA activities in cortical microvessels}

Although the vasculo-associated migration of GABAergic interneurons along the pial migratory route has been clearly shown [10], the cellular interactions and molecular mechanisms involved remain poorly understood (Fig. 8). It has been shown that deletion of VEGF from endothelial cells resulted in impaired angiogenesis and marked alteration of the GABAergic cortical lamination reinforcing the contribution of microvessels to GABAergic neuronal migration [43]. Moreover, several studies showed that migration of GABAergic neurons requires a close relationship with excitatory pyramidal cells (Fig. 8; [12, 44]). For example, recent data revealed that neuregulin 3 expressed by pyramidal excitatory neurons acts as a chemoattractive factor for GABAergic interneurons [12]. Nevertheless, very few data are available regarding mechanisms able to regulate the vasculo-associated migration of GABA interneurons. Using transcriptomic, proteomic, and pharmacological approaches, we previously showed that endothelial cells from neonate mice present specific phenotypic characteristics and, in particular, express high levels of functional NMDA receptors $[1,6,42]$. In line with this notion, glutamate has been shown in pathological conditions such as stroke to exacerbate the release and recycling activity of the endothelial proteases MMP-9 [45] and t-PA [46, 47]. Taken together, these data suggest that excitatory neurons would be able to regulate endothelial cell activity not only in pathological conditions but also in a developmental context. Consistent with this hypothesis, the present study showed that both MMP-9 and t-PA immunoreactivities were detected in microvessels from the PMR, whereas gel and in situ zymography revealed that glutamate induced a dose-dependent and MK801-dependent increase of the MMP-9 and t-PA activities along vessels of the PMR. In addition, the effects of glutamate on the vessel MMP-9 activity were abrogated in $\mathrm{t}-\mathrm{PA}^{-/-}$mice. This regionalized pattern of the glutamate-induced proteolytic 

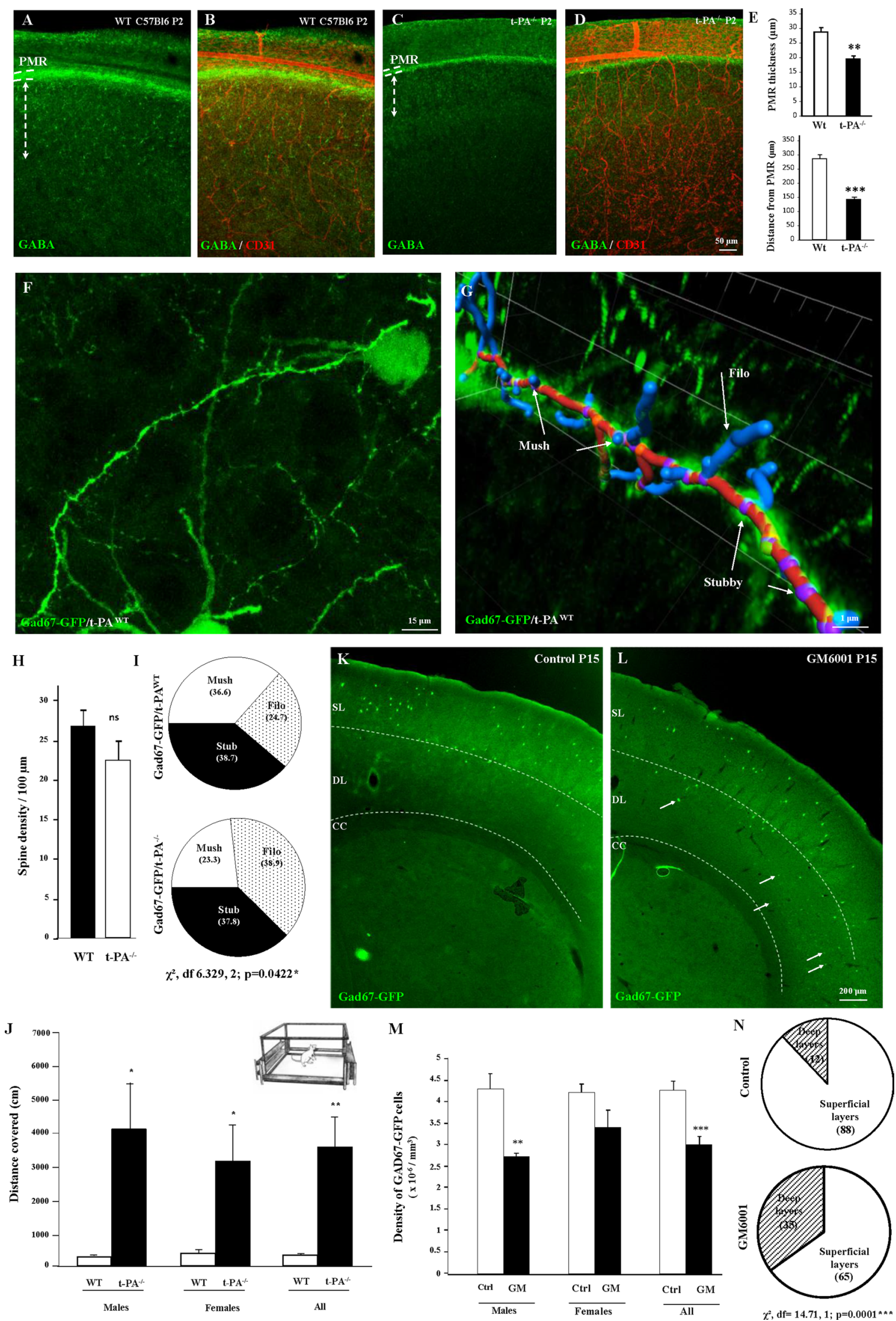
4Fig. 6 Effects of t-PA invalidation and in vivo GM6001 exposure on the cortical positioning and the spine morphology of GABA interneurons populating the superficial cortical layers. a-e Visualization of GABA interneurons $(\mathbf{a}-\mathbf{c})$ and microvessels $(\mathbf{b}, \mathbf{d})$ in P2 cortical slices from wild-type $(\mathbf{a}, \mathbf{b})$ and t-PA null $(\mathbf{c}, \mathbf{d})$ mice. Note the reduction of the PMR thickness (b, d, e, upper panel) and the reduced distance of GABA interneurons from the PMR (b, d, e, lower panel) in t-PA null mice. $\mathbf{f}$ Visualization of a Gad67-GFP neuron presenting dendritic spines in the superficial cortical layers of a wild-type mouse at P15. g Illustration of a graphic design obtained after spine analysis performed with the Filament tracer tool from the Imaris software. Three spine subtypes were analyzed: filopodia (Filo), mushrooms (Mush), and stubbies (Stub). Fiber is colored in red, mushrooms, and filopodia in blue, stubby in purple. h, i Quantification of the spine density (h) and the distribution of spine subtypes (i) in wild-type and $\mathrm{t}-\mathrm{PA}^{-/-}$mice at P15. j Quantification of the locomotor activity of wild-type and t-PA ${ }^{-/-}$mice at P15. $\mathbf{k}-\mathbf{m}$ Visualization $(\mathbf{k}, \mathbf{l})$ and quantification (m) of the positioning of Gad67-GFP neurons at P15 in control $(\mathbf{k}, \mathbf{m})$ and in vivo-exposed mice to the MMP inhibitor GM6001 (10 mg/kg; l, m). Note the presence of numerous ectopic cells in deep layers (l; arrows). $\mathbf{n}$ Quantification of the distribution of Gad67-GFP neurons between superficial and deep cortical layers in control and GM6001-treated mice. $n s$ not significant; ${ }^{*} p<0.05$; $* * p<0.01$; *** $p<0.001$ vs wild-type or control mice. The tests used for the statistical analysis, the number of independent experiments, the number of measures per experiment, and $p$ values are detailed in Table 1

activity would reinforce the notion of a regional contribution of MMP9 on brain development and plasticity. Considering that previous studies from the literature showed that cultured cortical endothelial cells from mouse neonates express NMDA receptors and that glutamate stimulates the release and the activity of MMP-9 [6], the present data support that in mouse neonates, glutamate stimulates MMP-9 activity in vessels from the PMR through NMDA receptor-dependent and t-PA-dependent mechanisms.

\section{Glutamate stimulates the vessel-associated migration of GABA interneurons via an NMDA-dependent mechanism}

In the mature brain, neurotransmitters are mainly released in synapses for communication between neurons [48]. However, during nervous system development, a trophic role of neurotransmitters implies neuronal release before their axons establish contacts with their target cells. Even if there is increasing evidence of such physiological roles, these extrasynaptic trophic roles are less understood [48]. Because MMP-9 is involved in proteolysis of the extracellular matrix [49], our data prompted us to investigate glutamate effects on the vasculo-dependent migration of GABA interneurons. Using immunohistochemistry performed from birth to P2, our data clearly showed a close interaction of GABA interneurons with microvessels of the cortical superficial layers. Video-tracking experiments indicated that glutamate was able to stimulate both tangential and radial vessel-associated migration, whereas MK801 induced an opposite effect. Consistent with these data, recent studies showed that neuronal projections from pyramidal cells are able to release factors such as neuregulin 3 that are involved in the control of GABA interneuron positioning [44, 50], and several lines of evidence indicated that glutamate released by excitatory cells in the developing brain can act as a guidance cue for migrating cells [51]. Altogether, the present data support that glutamate impacts endothelial protease activity via NMDA receptors and promotes the vessel-associated migration of GABA interneurons.

\section{t-PA invalidation and in vivo treatment with GM6001 alter the cortical positioning of GABA interneurons in superficial layers}

During embryonic life, interneurons migrate tangentially and then switch their mode of migration from tangential to radial as they invade the cortical plate $[10,52]$. Whereas cells from MGE and CGE take similar tangential migration paths with migrating above and below the cortical plate [52], an important sorting of GABA interneurons occurs during the first 2 postnatal weeks, leading to the final layerspecific positioning [39]. This developmental time-course prompts us to quantify the cortical positioning of GABA interneurons at P15. The results showed that in the superficial cortical layers, the density of Gad67-GFP interneurons as well as somatostatin-immunoreactive neurons was markedly reduced in both $\mathrm{t}-\mathrm{PA}^{-/-}$and GM6001-treated mice. In addition, because several studies reported dendritic spines in interneurons $[53,54]$, we analyzed spine morphology in the cortex of double-mutant Gad67-GFP/tPA ${ }^{-/-}$mice. Data revealed that in t-PA null mice, the distribution of dendritic spines was significantly impaired with an increased proportion of filopodia. These morphometric impairments were associated with an exacerbated locomotor activity of $\mathrm{t}_{-} \mathrm{PA}^{-/-}$mice at P15. Interestingly, several studies previously described delayed neuronal migration [37], modifications of the extracellular matrix [55], and long-term behavioral troubles of t-PA null mice related to disinhibition $[56,57]$. All these data suggest that the dysregulation of MMPs and $\mathrm{t}-\mathrm{PA}$ is associated with the impaired positioning of GABA interneurons populating the superficial cortical layers. However, even if our data showed strong t-PA and MMP-9 immunoreactivities/activities in vessels from the PMR, the fact that $\mathrm{t}-\mathrm{PA}^{-1-}$ mice are not conditional animals open new avenues of research. Indeed, a neuronal expression of t-PA has been also described in the literature [58] and it would be tempting to investigate, for example by developing t-PA floxed mice, the contribution of neuronal vs endothelial t-PA in neurovascular development. In addition, these results also raise new questioning regarding whether the positioning of GABA interneurons would be impaired in animals 
A

B6.129S4-Grin 1tm2Stl/J

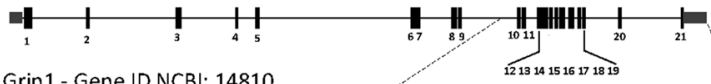

Grin1 - Gene ID NCBI: 14810

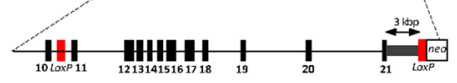

B6.FVB-Tg(Cdh5-cre)7Mlia/J

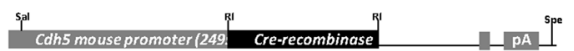

B

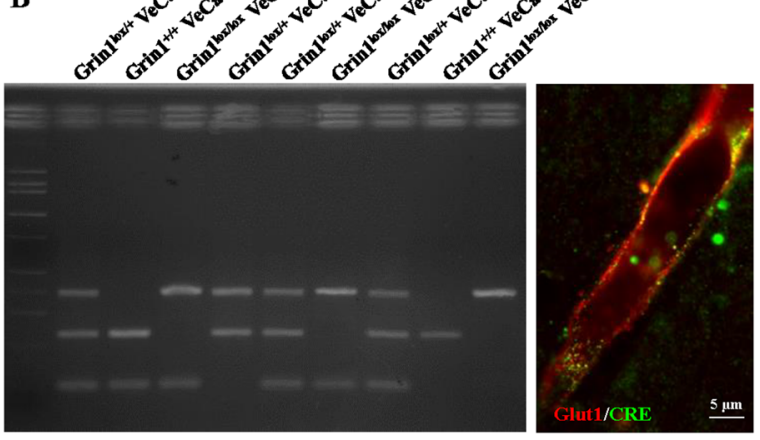

D

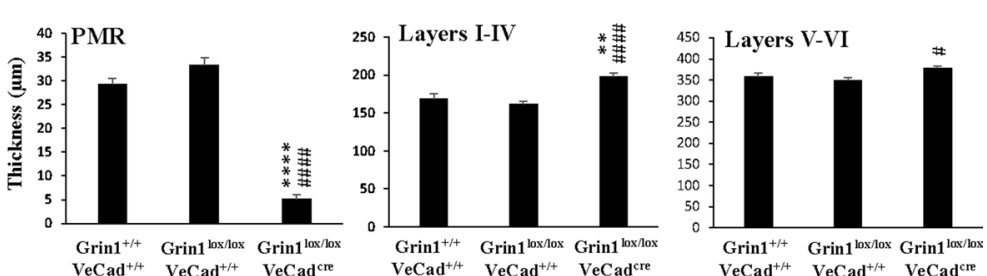

E
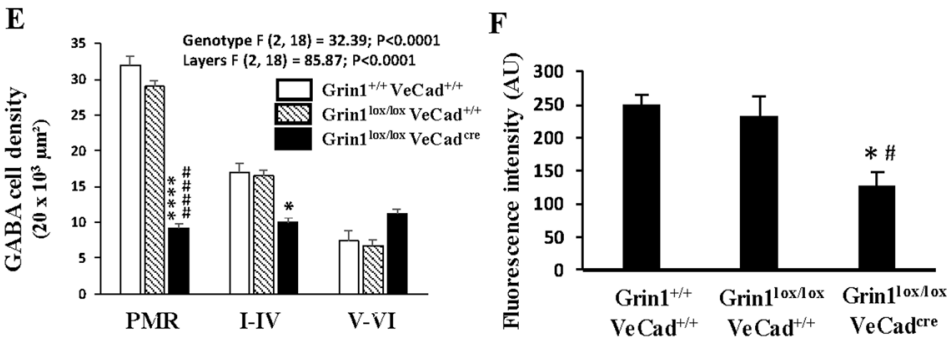

$100 \mu \mathrm{m}$
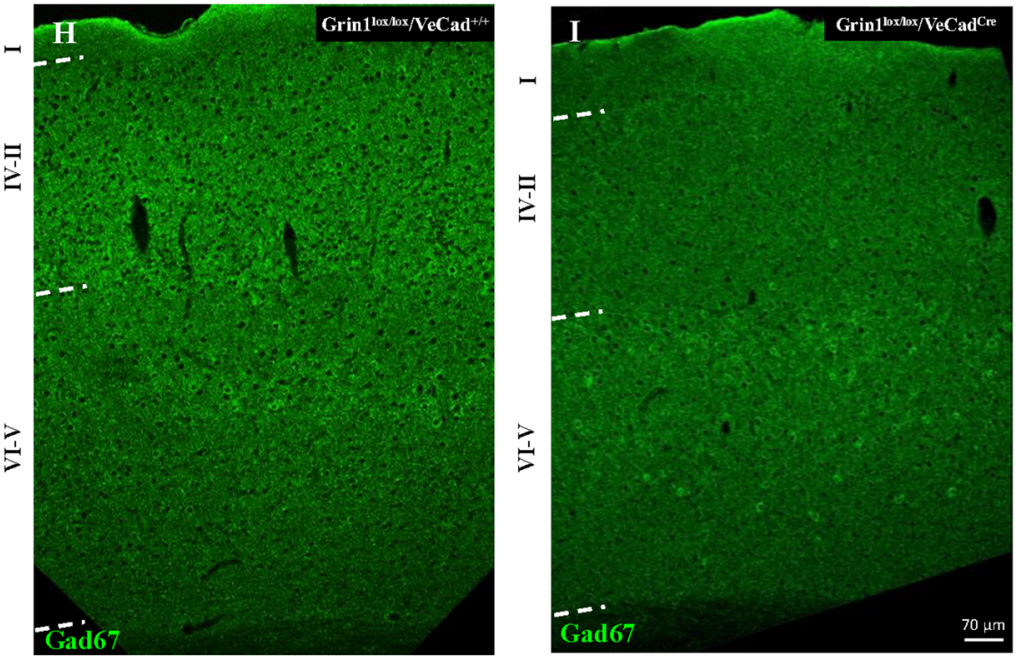

crig

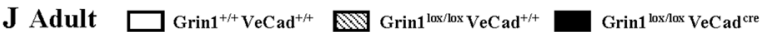
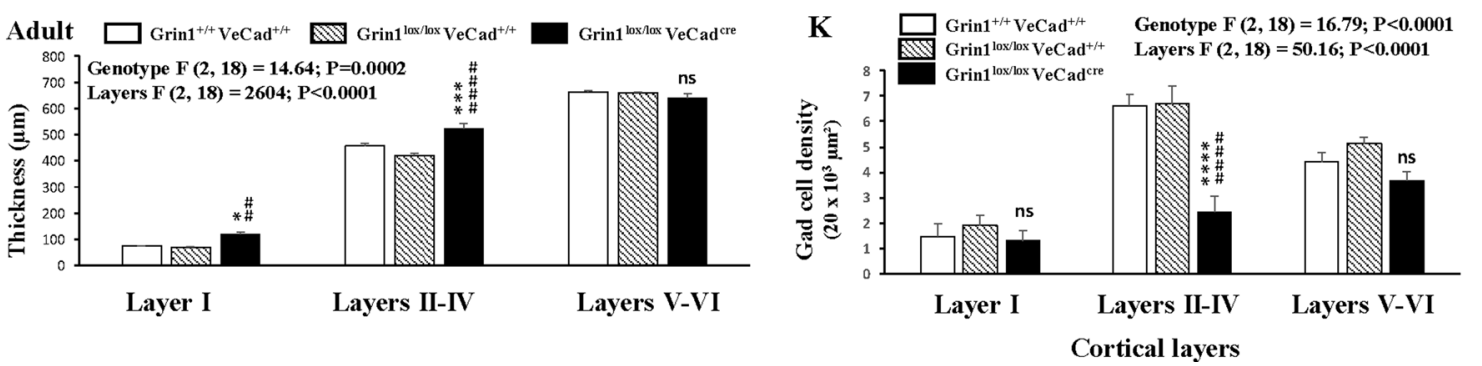
४Fig. 7 Effects of endothelial GluN1 invalidation on the pial migratory route and on the positioning of GABA interneurons. a, b Gene identity maps of floxed Grin1 and VE-Cadherin-Cre transgenic mice (a) used to generate $\mathrm{Grin} 1^{\text {lox } / l o x} / \mathrm{VeCad}^{\text {Cre }}$ transgenic mice (b; left panel). The endothelial expression of the Cre recombinase was controlled by immunohistochemistry (b; right panel). c Double immunohistochemistry experiments visualizing microvessels and GABA interneurons in the developing cortex of wild-type $\left(\mathrm{Grin}^{+/+} / \mathrm{VeCad}^{+/+}\right.$; left panel), $\mathrm{Grin}^{\text {lox } / l o x} / \mathrm{VeCad}^{+/+}$(middle panel), and Grin $1^{\text {lox/lox }} / \mathrm{VeCad}^{\text {Cre }}$ (right panel) mice at birth (P0). d, e Quantification of the thickness of the PMR, the developing superficial cortical layers (I-IV; d) and of the GABA interneuron density (e) in wild-type $\left(\mathrm{Grin}^{+/+} / \mathrm{VeCad}^{+/+}\right)$, Grin $1^{\text {lox/lox }} / \mathrm{VeCad}^{+/+}$, and Grin $1^{\text {lox/lox }} / \mathrm{VeCad}^{\text {Cre }}$ mice at birth. f Quantification by videomicroscopy of the effect of glutamate $(100 \mu \mathrm{M})$ on the MMP-9-like activity in cortical slices from wild-type $\left(\mathrm{Grin}^{+/+}\right.$/ $\left.\mathrm{VeCad}^{+/+}\right)$, Grin $1^{\text {lox/lox }} / \mathrm{VeCad}^{+/+}$, and $\mathrm{Grin} 1^{\text {lox/lox}} / \mathrm{VeCad}{ }^{\text {Cre }}$ mice. Images of the in situ zymographies are provided in Supplementary Fig. 8. g-i Visualization at low magnification of the positioning of Gad67-positive neurons in the neocortex of adult wild-type $\left(\mathrm{Grin}^{+/+} / \mathrm{VeCad}^{+/+} ; \mathbf{g}\right)$, Grin $1^{\text {lox } / l o x} / \mathrm{VeCad}^{+/+}$(h) and $\mathrm{Grin} 1^{\text {lox/lox } /}$ $\mathrm{VeCad}^{\mathrm{Cre}}$ (i) mice. Note a depopulation of Gad67-immunoreactive cells in the superficial cortical layers in Grin $1^{\text {lox/lox }} / \mathrm{VeCad}^{\mathrm{Cre}}$ mice. j Quantification of the thickness of the layer I, superficial layers IIIV and deep layers V-VI in adult wild-type $\left(\mathrm{Grin}^{+/+} / \mathrm{VeCad}^{+/+}\right)$, Grin $1^{l o x} / / o x / \mathrm{VeCad}^{+/+}$, and Grin $1^{\text {lox/lox}} / \mathrm{VeCad}^{C r e}$ mice. k Quantification of the density of Gad-immunoreactive cells in the layer I, superficial layers II-IV and deep layers V-VI in adult wild-type $\left(\mathrm{Grin}^{+/+}\right.$/ $\left.\mathrm{VeCad}^{+/+}\right)$, Grin $1^{\text {lox } / \text { lox }} / \mathrm{VeCad}^{+/+}$, and Grin $1^{\text {lox/lox }} / \mathrm{VeCad}^{\text {Cre }}$ mice. $n s$ not significant; $* p<0.05 ; * * p<0.01 ; * * * p<0.001 ; * * * * p<0.0001$

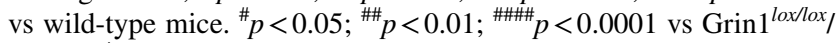
$\mathrm{VeCad}^{+/+}$. The tests used for the statistical analysis, the number of independent experiments, the number of measures per experiment, and $p$ values are detailed in Table 1

perinatally exposed to factors with NMDA-antagonist properties such as ketamine.

\section{The positioning of GABA interneurons in the cortical superficial layers is impaired in $\mathrm{Grin}{ }^{\text {lox/lox }} / \mathrm{VeCad}{ }^{\text {Cre }}$ mice}

Previous in vitro studies revealed that neonatal endothelial cells express NMDA receptors [6]. In particular, glutamate was shown to induce a MK801-dependent activation of MMP-9 in cultured endothelial cells supporting a direct effect of glutamate on this cell type. However, because in the developing brain, NMDA receptors are expressed by numerous cell types including immature GABA interneurons [41], we characterized the positioning of GABA interneurons in Grin $1^{l o x} / l o x / \mathrm{VeCad}{ }^{C r e}$ mice. At birth, data revealed a marked reduction of the PMR thickness, a decrease of the MMP9-like activity along vessels from the PMR and a significant depopulation of GABA interneurons in the developing superficial layers. Similarly, in adult Grin $1^{l o x / l o x} / \mathrm{VeCad}^{C r e}$ mice, the positioning of GABA interneurons in the cortical superficial layers II-IV was markedly impaired with a strong decreased of Gad67 immunoreactive neurons. In addition, ectopic cells were found in the cortical layers V-VI. Interestingly, the presence of ectopic cells in deep layers was also observed in animals in vivo-exposed to GM6001. The presence of such ectopic cells in deep layers would be explained by the description in the literature of different (periventricular and pial) migratory routes of GABA interneurons and would suggest distinct mechanisms controlling cell migration [10]. Interestingly, in alcohol-exposed animal models, it has been also described a depopulation of GABA interneurons in superficial cortical layers, while ectopic cells were found in layer $\mathrm{V}$ [59]. Taken together, it is tempting to bring together our present data and the NMDA-antagonist properties of ethanol.

In conclusion, results from the present study support a role of the endothelial NMDA receptor in the control of the late vessel-associated migration of GABA interneurons populating the superficial cortical layers. At a neurodevelopmental level, they show that MMP-9 immunoreactivity is detected in microvessels along the PMR and that t-PA and the endothelial NMDA receptor actively contribute in the control of the MMP-9 activity as well as in the positioning of GABA interneurons in the superficial cortical layers. At a pathophysiological level, the present data reinforce the debate regarding the use of molecules with NMDA-antagonist properties such as anesthetics during perinatal life when a late vasculo-associated migration of interneurons still occurs.

Acknowledgements This work was supported by the Normandy University (ERI28, UMR1245), the Institut National de la Santé et Recherche Médicale (INSERM; ERI28, UMR1245), the Conseil Régional de Normandie, the LARC-Neuroscience network, the french National Research Agency (ANR) and the Regional Platform for Cell Imaging (PRIMACEN), the Fondation Paralysie Cérébrale, the Fondation de France, the European funds FEDER. This study is labeled by the competitiveness cluster Medicen-Paris Region. CL is a recipient of a fellowship from the Région Normandie.

Open Access This article is distributed under the terms of the Creative Commons Attribution 4.0 International License (http://creativeco mmons.org/licenses/by/4.0/), which permits unrestricted use, distribution, and reproduction in any medium, provided you give appropriate credit to the original author(s) and the source, provide a link to the Creative Commons license, and indicate if changes were made.

\section{References}

1. Porte B, Hardouin J, Zerdoumi Y, Derambure C, Hauchecorne M, Dupre N, Obry A, Lequerre T, Bekri S, Gonzalez B, Flaman JM, Marret S, Cosette P, Leroux P (2017) Major remodeling of brain microvessels during neonatal period in the mouse: a proteomic and transcriptomic study. J Cereb Blood Flow Metab 37:495-513

2. Tan X, Liu WA, Zhang XJ, Shi W, Ren SQ, Li Z, Brown KN, Shi SH (2016) Vascular influence on ventral telencephalic progenitors and neocortical interneuron production. Dev Cell 36:624-638

3. Borrell V, Marín O (2006) Meninges control tangential migration of hem-derived Cajal-Retzius cells via CXCL12/CXCR3 signaling. Nat Neurosci 9:1284-1293 


\section{Postnatal day 2 mouse neonates}
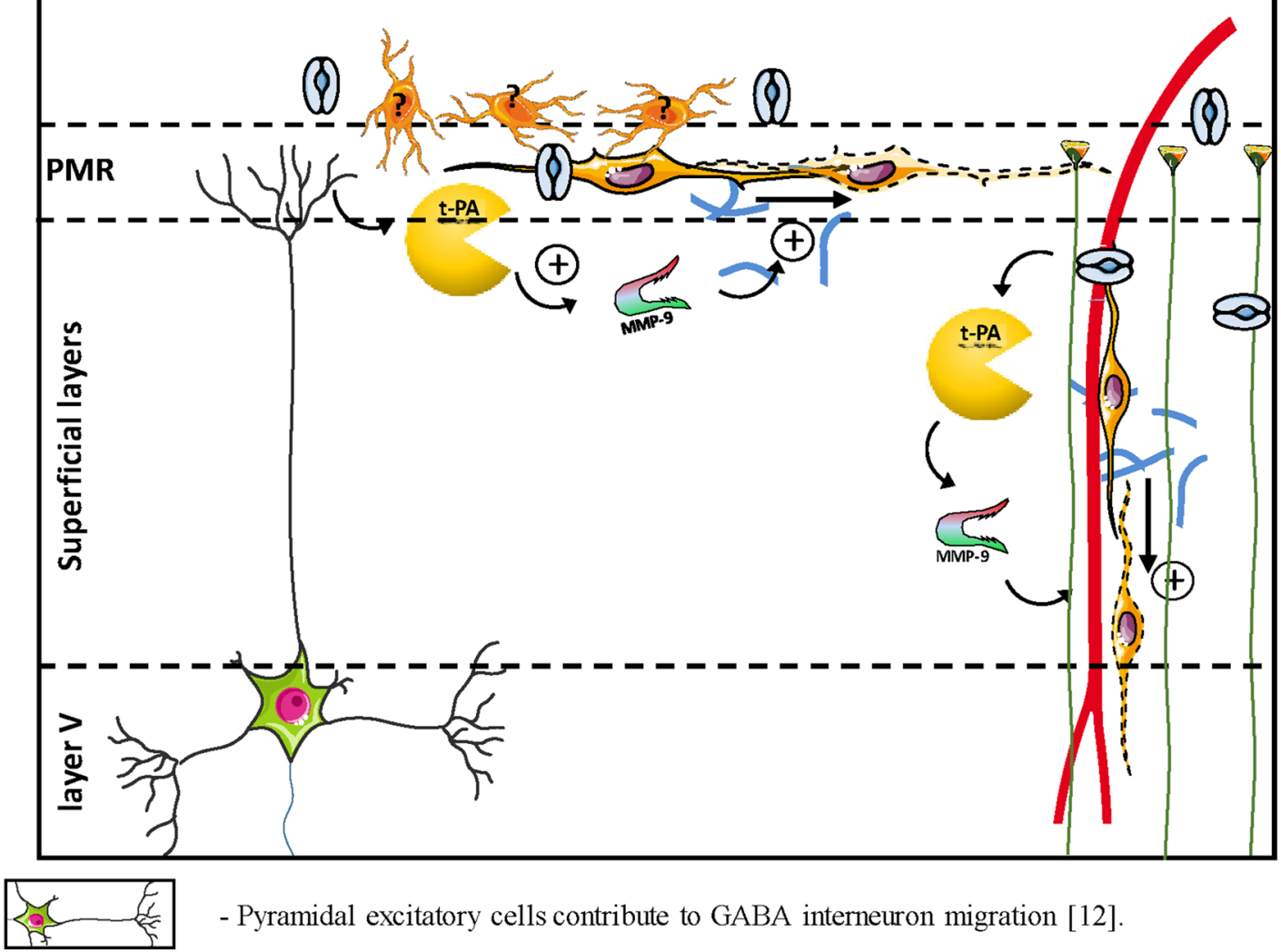

- Pyramidal excitatory cells contribute to GABA interneuron migration [12].

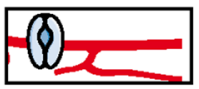

- In the developing cortex, in addition to migrating GABA interneurons [41] or radial glia [58], GluN1 subunits are expressed by endothelial cells,
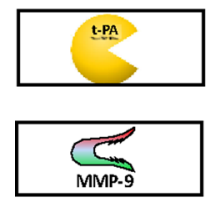

- Glutamate stimulates t-PA activity in vessels from the PMR.

- This effect is blocked by MK801 and also observed on cultured neonatal endothelial cells [6].

- Glutamate stimulates MMP-9 activity in vessels from the PMR

- This effect is blocked by MK801 and abolished in $\mathrm{t}-\mathrm{PA}^{-/-}$mice.

- This effect is also observed on cultured neonatal endothelial cells [6].

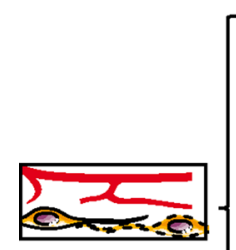

- GABA interneurons migrating along the PMR are in close interaction with vessels [11].

- GABA interneurons entering the cortex are preferentialy associated with radial vessels.

- Glutamate stimulates tangential and radial GABA interneuron migration along vessels.

- MK801 inhibits the migration speed.

- In t-PA ${ }^{-/-}$mice, the thickness of the PMR is reduced- The positioning of interneurons is altered.

- In Grinl lox/lox/VeCad ${ }^{C r e}$ mice, the thickness of the PMR is reduced.

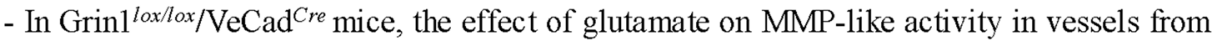
the PMR is reduced.

- In Grin1 $1^{\text {lox/lox}} / \mathrm{VeCad}^{C r e}$ mice, the positioning of interneurons is impaired.
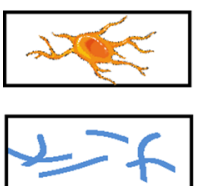

- GFAP-positive cells are lining the PMR - No evidence in the literature for their contribution in the control of interneuron migration (?). GFAP-positive cells are also described along the rostral migratory stream (RMS) in adult mice [60].

- Extracellular matrix.
Fig. 8 Graphical abstract integrating highlights from the present study and several studies from the literature positioning the contribution of the endothelial NMDA receptor in the regulation of MMP-9 activity and the vessel-associated migration of GABA interneuron arising from the PMR. Highlights are described and classified by graphical items. Data from the literature are mentioned by numbers in brackets which refer to the reference list of the main manuscript 
4. Zarbalis K, Choe Y, Siegenthaler JA, Orosco LA, Pleasure SJ (2012) Meningeal defects alter the tangential migration of cortical interneurons in Foxc1hith/hith mice. Neural Dev 7:2

5. Lecointre M, Hauchecorne M, Chaussivert A, Marret S, Leroux P, Jegou S, Leroux-Nicollet I, Gonzalez BJ, Henry VJ (2014) The efficiency of glutamate uptake differs between neonatal and adult cortical microvascular endothelial cells. J Cereb Blood Flow Metab 34:764-767

6. Legros H, Launay S, Roussel BD, Marcou-Labarre A, Calbo S, Catteau J, Leroux P, Boyer O, Ali C, Marret S, Vivien D, Laudenbach V (2009) Newborn- and adult-derived brain microvascular endothelial cells show age-related differences in phenotype and glutamate-evoked protease release. J Cereb Blood Flow Metab 29:1146-1158

7. Barkho BZ, Munoz AE, Li X, Li L, Cunningham LA, Zhao X (2008) Endogenous matrix metalloproteinase (MMP)-3 and MMP-9 promote the differentiation and migration of adult neural progenitor cells in response to chemokines. Stem Cells 26:3139-3149

8. Siconolfi LB, Seeds NW (2001) Mice lacking tPA, uPA, or plasminogen genes showed delayed functional recovery after sciatic nerve crush. J Neurosci 21:4348-4355

9. Inada $H$, Watanabe $M$, Uchida $T$, Ishibashi $H$, Wake $H$, Nemoto T, Yanagawa Y, Fukuda A, Nabekura J (2011) GABA regulates the multidirectional tangential migration of GABAergic interneurons in living neonatal mice. PLoS One 6:e27048

10. Luhmann HJ, Fukuda A, Kilb W (2015) Control of cortical neuronal migration by glutamate and GABA. Front Cell Neurosci 9:1-15

11. Won C, Lin Z, Kumar TP, Li S, Ding L, Elkhal A, Szabó G, Vasudevan A (2013) Autonomous vascular networks synchronize GABA neuron migration in the embryonic forebrain. Nat Commun 4:2149

12. Bartolini G, Sánchez-Alcañiz JA, Osório C, Valiente M, GarcíaFrigola C, Marín O (2017) Neuregulin 3 mediates cortical plate invasion and laminar allocation of GABAergic interneurons. Cell Rep 18:1157-1170

13. Aligny C, Roux C, Dourmap N, Ramdani Y, Do-Rego JC, Jégou S, Leroux P, Leroux-Nicollet I, Marret S, Gonzalez BJ (2014) Ketamine alters cortical integration of GABAergic interneurons and induces long-term sex-dependent impairments in transgenic Gad67-GFP mice. Cell Death Dis 5:e1311

14. Desfeux A, El Ghazi F, Jégou S, Legros H, Marret S, Laudenbach V, Gonzalez BJ (2010) Dual effect of glutamate on GABAergic interneuron survival during cerebral cortex development in mice neonates. Cereb Cortex 20:1092-1108

15. Girault V, Gilard V, Marguet F, Lesueur C, Hauchecorne M, Ramdani Y, Laquerrière A, Marret S, Jégou S, Gonzalez BJ, Brasse-Lagnel C, Bekri S (2017) Prenatal alcohol exposure impairs autophagy in neonatal brain cortical microvessels. Cell Death Dis 8:e2610

16. Roux C, Aligny C, Lesueur C, Girault V, Brunel V, Ramdani Y, Genty D, Driouich A, Laquerrière A, Marret S, Brasse-Lagnel C, Gonzalez BJ, Bekri S (2015) NMDA receptor blockade in the developing cortex induces autophagy-mediated death of immature cortical GABAergic interneurons: an ex vivo and in vivo study in Gad67-GFP mice. Exp Neurol 267:177-193

17. Wang Q, Shen FY, Zou R, Zheng JJ, Yu X, Wang YW (2017) Ketamine-induced apoptosis in the mouse cerebral cortex follows similar characteristic of physiological apoptosis and can be regulated by neuronal activity. Mol Brain 10:24

18. Xu G, Broadbelt KG, Haynes RL, Folkerth RD, Borenstein NS, Belliveau RA, Trachtenberg FL, Volpe JJ, Kinney HC (2011) Late development of the GABAergic system in the human cerebral cortex and white matter. J Neuropathol Exp Neurol $70: 841-858$
19. Bhutta AT (2007) Ketamine: a controversial drug for neonates. Semin Perinatol 31:303-308

20. Salmeen KE, Jelin AC, Thiet MP (2014) Perinatal neuroprotection. F1000Prime ep 6:6

21. Volpe JJ (2009) Brain injury in premature infants: a complex amalgam of destructive and developmental disturbances. Lancet Neurol 8:110-124

22. Hardingham GE, Do KQ (2016) Linking early-life NMDAR hypofunction and oxidative stress in schizophrenia pathogenesis. Nat Rev Neurosci 17:125-134

23. Kaushal S, Tamer Z, Opoku F, Forcelli PA (2016) Anticonvulsant drug-induced cell death in the developing white matter of the rodent brain. Epilepsia 57:727-734

24. Nakazawa K, Jeevakumar V, Nakao K (2017) Spatial and temporal boundaries of NMDA receptor hypofunction leading to schizophrenia. NPJ Schizophr 3:7

25. Oliva AA Jr, Jiang M, Lam T, Smith KL, Swann JW (2000) Novel hippocampal interneuronal subtypes identified using transgenic mice that express green fluorescent protein in GABAergic interneurons. J Neurosci 20:3354-3368

26. Carmeliet P, Schoonjans L, Kieckens L, Ream B, Degen J, Bronson R, De Vos R, van den Oord JJ, Collen D, Mulligan RC (1994) Physiological consequences of loss of plasminogen activator gene function in mice. Nature 368:419-424

27. Marret S, Mukendi R, Gadisseux JF, Gressens P, Evrard P (1995) Effect of ibotenate on brain development: an excitotoxic mouse model of microgyria and posthypoxic-like lesions. J Neuropathol Exp Neurol 54:358-370

28. Mesplès B, Plaisant F, Fontaine RH, Gressens P (2005) Pathophysiology of neonatal brain lesions: lessons from animal models of excitotoxicity. Acta Paediatr 94:185-190

29. Roux C, Lesueur C, Aligny C, Brasse-Lagnel C, Genty D, Marret S, Laquerrière A, Bekri S, Gonzalez BJ (2014) 3-MA inhibits autophagy and favors long-term integration of grafted Gad67-GFP GABAergic precursors in the developing neocortex by preventing apoptosis. Cell Transpl 23:1425-1450

30. Bénard M, Lebon A, Komuro H, Vaudry D, Galas L (2015) Ex vivo imaging of postnatal cerebellar granule cell migration using confocal macroscopy. J Vis Exp 99:e52810

31. Khan A, de Jong LA, Kamenski ME, Higa KK, Lucero JD, Young JW, Behrens MM, Powell SB (2017) Adolescent GBR12909 exposure induces oxidative stress, disrupts parvalbumin-positive interneurons, and leads to hyperactivity and impulsivity in adult mice. Neuroscience 345:166-175

32. Sifringer M, Stefovska V, Zentner I, Hansen B, Stepulak A, Knaute C, Marzahn J, Ikonomidou C (2007) The role of matrix metalloproteinases in infant traumatic brain injury. Neurobiol Dis 25:526-535

33. Marín O (2013) Cellular and molecular mechanisms controlling the migration of neocortical interneurons. Eur J Neurosci 38:2019-2029

34. Zhao BQ, Wang S, Kim HY, Storrie H, Rosen BR, Mooney DJ, Wang X, Lo EH (2006) Role of matrix metalloproteinases in delayed cortical responses after stroke. Nat Med 12:441-445

35. Joseph JV, van Roosmalen IA, Busschers E, Tomar T, Conroy S, Eggens-Meijer E, Peñaranda Fajardo N, Pore MM, Balasubramanyian V, Wagemakers M, Copray S, den Dunnen WF, Kruyt FA (2015) Serum-induced differentiation of glioblastoma neurospheres leads to enhanced migration/invasion capacity that is associated with increased MMP9. PLoS One 10:e0145393

36. Chaturvedi M, Kaczmarek L (2014) Mmp-9 inhibition: a therapeutic strategy in ischemic stroke. Mol Neurobiol 49:563-573

37. Seeds NW, Basham ME, Haffke SP (1999) Neuronal migration is retarded in mice lacking the tissue plasminogen activator gene. Proc Natl Acad Sci USA 96:14118-14123 
38. Turner RJ, Sharp FR (2016) Implications of MMP9 for blood brain barrier disruption and hemorrhagic transformation following ischemic stroke. Front Cell Neurosci 4(10):56

39. Southwell DG, Paredes MF, Galvao RP, Jones DL, Froemke RC, Sebe JY, Alfaro-Cervello C, Tang Y, Garcia-Verdugo JM, Rubenstein JL, Baraban SC, Alvarez-Buylla A (2012) Intrinsically determined cell death of developing cortical interneurons. Nature 491:109-113

40. Pham LD, Hayakawa K, Seo JH, Nguyen MN, Som AT, Lee BJ, Guo S, Kim KW, Lo EH, Arai K (2012) Crosstalk between oligodendrocytes and cerebral endothelium contributes to vascular remodeling after white matter injury. Glia 60:875-881

41. Deng R, Kao JPY, Kanold PO (2017) Distinct translaminar glutamatergic circuits to GABAergic interneurons in the neonatal auditory cortex. Cell Rep 19:1141-1150

42. Henry VJ, Lecointre M, Laudenbach V, Ali C, Macrez R, Jullienne A, Berezowski V, Carmeliet P, Vivien D, Marret S, Gonzalez BJ, Leroux P (2013) High t-PA release by neonate brain microvascular endothelial cells under glutamate exposure affects neuronal fate. Neurobiol Dis 50:201-208

43. Li S, Haigh K, Haigh JJ, Vasudevan A (2013) Endothelial VEGF sculpts cortical cytoarchitecture. J Neurosci 33:14809-14815

44. Ciceri G, Dehorter N, Sols I, Huang ZJ, Maravall M, Marín O (2013) Lineage-specific laminar organization of cortical GABAergic interneurons. Nat Neurosci 16:1199-1210

45. Michaluk P, Kaczmarek L (2007) Matrix metalloproteinase-9 in glutamate-dependent adult brain function and dysfunction. Cell Death Differ 14:1255-1258

46. Cassé F, Bardou I, Danglot L, Briens A, Montagne A, Parcq J, Alahari A, Galli T, Vivien D, Docagne F (2012) Glutamate controls tPA recycling by astrocytes, which in turn influences glutamatergic signals. J Neurosci 32:5186-5199

47. Gaberel T, Macrez R, Gauberti M, Montagne A, Hebert M, Petersen KU, Touze E, Agin V, Emery E, Ali C, Vivien D (2013) Immunotherapy blocking the tissue plasminogen activatordependent activation of $N$-methyl-D-aspartate glutamate receptors improves hemorrhagic stroke outcome. Neuropharmacology 67:267-271

48. Ruediger T, Bolz J (2007) Neurotransmitters and the development of neuronal circuits. Adv Exp Med Biol 621:104-115

49. Zechariah A, ElAli A, Hermann DM (2010) Combination of tissue-plasminogen activator with erythropoietin induces bloodbrain barrier permeability, extracellular matrix disaggregation, and DNA fragmentation after focal cerebral ischemia in mice. Stroke 41:1008-1012

50. Lodato S, Rouaux C, Quast KB, Jantrachotechatchawan C, Studer M, Hensch TK, Arlotta P (2011) Excitatory projection neuron subtypes control the distribution of local inhibitory interneurons in the cerebral cortex. Neuron 69:763-779

51. Nguyen L, Rigo JM, Rocher V, Belachew S, Malgrange B, Rogister B, Leprince P, Moonen G (2001) Neurotransmitters as early signals for central nervous system development. Cell Tissue Res 305:187-202

52. Miyoshi G, Fishell G (2011) GABAergic interneuron lineages selectively sort into specific cortical layers during early postnatal development. Cereb Cortex 21:845-852

53. Guirado R, Perez-Rando M, Sanchez-Matarredona D, Castillo-Gómez E, Liberia T, Rovira-Esteban L, Varea E, Crespo C, Blasco-Ibáñez JM, Nacher J (2014) The dendritic spines of interneurons are dynamic structures influenced by PSA-NCAM expression. Cereb Cortex 24:3014-3024

54. Keck T, Scheuss V, Jacobsen RI, Wierenga CJ, Eysel UT, Bonhoeffer T, Hübener M (2011) Loss of sensory input causes rapid structural changes of inhibitory neurons in adult mouse visual cortex. Neuron 71:869-882

55. Trotter JH, Lussier AL, Psilos KE, Mahoney HL, Sponaugle AE, Hoe HS, Rebeck GW, Weeber EJ (2014) Extracellular proteolysis of reelin by tissue plasminogen activator following synaptic potentiation. Neuroscience 274:299-307

56. Pawlak R, Magarinos AM, Melchor J, McEwen B, Strickland S (2003) Tissue plasminogen activator in the amygdala is critical for stress-induced anxiety-like behavior. Nat Neurosci 6:168-174

57. Pothakos K, Robinson JK, Gravanis I, Marsteller DA, Dewey SL, Tsirka SE (2010) Decreased serotonin levels associated with behavioral disinhibition in tissue plasminogen activator deficient $\left(\mathrm{tPA}^{-1-}\right.$ ) mice. Brain Res 1326:135-142

58. Pasquet N, Douceau S, Naveau M, Lesept F, Louessard M, Lebouvier L, Hommet Y, Vivien D, Bardou I (2018) Tissue-type plasminogen activator controlled corticogenesis through a mechanism dependent of NMDA receptors expressed on radial glial cells. Cereb Cortex 1:1. https://doi.org/10.1093/cercor/bhy119

59. Shenoda BB (2017) An overview of the mechanisms of abnormal GABAergic interneuronal cortical migration associated with prenatal ethanol exposure. Neurochem Res 42:1279-1287

60. Snapyan M, Lemasson M, Brill MS, Blais M, Massouh M, Ninkovic J, Gravel C, Berthod F, Götz M, Barker PA, Parent A, Saghatelyan A (2009) Vasculature guides migrating neuronal precursors in the adult mammalian forebrain via brain-derived neurotrophic factor signaling. J Neurosci 29:4172-4188

61. Vanlandewijck M, He L, Mäe MA, Andrae J, Ando K, Del Gaudio F, Nahar K, Lebouvier T, Laviña B, Gouveia L, Sun Y, Raschperger E, Räsänen M, Zarb Y, Mochizuki N, Keller A, Lendahl U, Betsholtz C (2018) A molecular atlas of cell types and zonation in the brain vasculature. Nature 554:475-480

Publisher's Note Springer Nature remains neutral with regard to jurisdictional claims in published maps and institutional affiliations. 